Original Article

Received/Accepted

Dates

17.04.2021/09.05.2021

DOI

10.52096/jsrbs.6.1.7.13.16
Journal of Social Research and Behavioral Sciences

Sosyal Araştırmalar ve Davranış Bilimleri Dergisi

ISSN:2149-178X

Volume: 7 Issue: 13 Year: 2021

\title{
Örgütsel Çeviklik Açısından Örgüt Kültürü ve Firma Performansı Üzerine Bir Alan
}

Araştırması

\author{
Doktora Öğr. Emine SEVER \\ İstanbul Kültür Üniversitesi \\ İktisadi İdari Bilimler Fakültesi \\ İşletme Bölümü \\ Prof. Dr. Mahmut PAKSOY \\ İstanbul Kültür Üniversitesi \\ İktisadi İdari Bilimler Fakültesi \\ İşletme Bölümü
}

\section{Özet}

Bu çalışmanın amacı, örgüt kültürünün firma performansına etkisinde, örgütsel çevikliğin aracılık etkisini tespit edebilmektir. Çalışma kapsamında öncelikle örgüt kültürü̈, örgütsel çeviklik ve firma performansı hakkında kavramsal çerçeve oluşturulmuş, ardından araştırma kapsamında gerçekleştirilen anket uygulamasından elde edilen bulgu ve sonuçlara yer verilmiştir. Araştırma örneklemini, İstanbul, Ankara, İzmir, Tekirdağ, Kocaeli ve Zonguldak illerindeki İmalat, Hizmet, IT, Perakende ve Tarım sektörlerine ait 140 firma çalışanı oluşturmaktadır. Anket verileri, tesadüfî olmayan kolayda örnekleme yöntemi kullanılarak, çevrimiçi anket yöntemiyle toplanmıştır. Araştırmada nicel veri analizi uygulanmıştır. 5'li Likert ölçeği kullanılan anket formu, demografik sorular ile örgüt kültürü, örgütsel çeviklik ve firma performansı ölçeklerinden oluşmaktadır. Model olarak yapısal eşitlik modellemesi tercih edilen araştırmada verilerin analizinde SPSS 25.0 ve AMOS 22 paket programları kullanılmıştır. Geçerlilik testi için doğrulayıcı faktör analizi, güvenilirlik için Cronbach's alpha değerlerine bakılmıştır. Çalışma bulgularına göre klan, adhokrasi ve hiyerarşi kültürlerinin firma performansına etkisinde, örgütsel çevikliğin aracılık etkisi bulunmaktadır. Fakat, pazar kültürünün aracılık etkisi tespit edilememiştir. Demografik özellikler açısından da örgüt kültürü, örgütsel çeviklik ve firma performansı algıları arasında anlamlı farklıklar tespit edilmiştir.

Anahtar Kelimeler: Örgüt Kültürü, Örgütsel Çeviklik, Firma Performans1 


\title{
A Field Research on Organizational Culture and Firm Performance in Terms of Organizational Agility
}

\begin{abstract}
The aim of this study is to determine the mediating effect of organizational agility on the impact of organizational culture on firm performance. Within the scope of the study, firstly, a conceptual framework about organizational culture, organizational agility and firm performance was created, and then the findings and results obtained from the survey application conducted within the scope of the research were included. The research sample consists of 140 company employees belonging to the Manufacturing, Service, IT, Retail and Agriculture sectors in the provinces of Istanbul, Ankara, Izmir, Tekirdağ, Kocaeli and Zonguldak. The survey data were collected by the online survey method using the non-coincidental convenience sampling method. Quantitative data analysis was applied in the research. The questionnaire form using a 5-point Likert scale consists of demographic questions and organizational culture, organizational agility and firm performance scales. In the study, in which structural equation modeling was preferred as a model, SPSS 25.0 and AMOS 22 package programs were used in the analysis of the data. Confirmatory factor analysis was checked for validity test and Cronbach's alpha values were checked for reliability. According to the findings of the study, organizational agility has a mediating effect on the effect of clan, adhocracy and hierarchy cultures on firm performance. However, the mediating effect of market culture could not be determined. In terms of demographic characteristics, significant differences were determined between perceptions of organizational culture, organizational agility and firm performance.
\end{abstract}

Keywords: Organizational Culture, Organizational Agility, Firm Performance

\section{Giriş}

Günümüzde değişen teknolojik ve çevresel koşullar örgütler için yeni firsatlar ve tehditler ortaya çıkartabilmektedir. Örgütlerin yaşamlarını devam ettirebilmesi, bu fırsat ve tehditleri rekabet avantajına dönüştürerek çevik davranmaları ve bunun sonucu olarak da firma performanslarını artırmaları gerekebilmektedir.

Buradan yola çıkarak, bu çalışma farklı sektör, yaş ve büyüklükteki örgütlerin, içinde bulundukları rekabet ortamında sürdürülebilir olmalarını sağlayacak olan çeviklik olgusunda, örgüt kültürünün etkisini ortaya koymayı hedeflemektedir. Ayrıca, farklı örgüt kültürlerinin ve çeviklik düzeylerinin, firma performansı üzerindeki etkisi de araştırmaya dahil edilmiştir. 
Çalışmada örgüt kültürü modellerinden, Cameron Quinn’nin modelinden yararlanılmıştır. Literatürde örgüt kültürü, örgütsel çeviklik ve firma performansının aynı anda ele alındığı ve müşteri tutma, yenilik, finansal performansın birlikte değerlendirildiği bir araştırmaya rastlanılamamıştır.

Bu araştırmada firma performansı ile kastedilen, kurumun veya örgütün performansıdır. Porter'a göre (1991) firma performansı, işletme stratejilerinin belirli bir dönem sonunda uygulamalardaki ve çıktılardaki hedeflere ulaşma derecesini, başka bir deyişle başarı düzeyini belirtmektedir. Firma performansı, temel ekonomik amaçlarına ulaşma düzeyinin yanı sıra, işletmenin değişen çevre koşullarına uyum becerisinin göstergesi ve rekabetteki varlığının sürdürülebilirliğinde yenilik başarısı ile de yakından ilgilidir. Bundan dolayı yenilik performansı, oldukça önemli bir firma performans kriteri olarak kabul edilmektedir (Hagedoorn \& Cloodt, 2003). Bu çalışmada ayrıca, örgütsel çevikliğin tanımındaki tüketiciyi memnun etme ifadesinden yola çıkarak, firma performansında müşteri tutma performansı da kullanılmıştır. Ginn vd. (2010) müşteri tutma performansını, müşterinin firmayla olan bir iş ilişkisini sürdüğünü beyan etmesi olarak tanımlar. Firma stratejileri genelde finansal performansla de ğerlendirmeye alınır. Bunun sebebi, firmaların temel ekonomik hedeflerini gerçekleştirme derecesi hakkında araştırmacılara fikir vermesi düşüncesidir. Finansal performans bir kriter olarak ele alındığında değerlendirme için sıklıkla başvurulan ölçüm değişkenleri; ciro karlılığı, toplam varlık kârlılı̆̆ı, yatırımların geri donuş, oranı, öz sermaye kârlılığg1, vergilerden önce elde edilen gelirler, net gelirler gibi ekonomik hedeflerin değerlendirilmesine yönelik göstergelere ilişkin kombinasyonlar kullanılmaktadır (Venkatraman \& Ramanujam, 1987).

\section{Kavramsal Çerçeve}

\section{1. Örgüt kültürrü}

Örgüt kültürü, işletmelerde çalışan örgüt üyelerinin, ortak davranış, tutum ve işbirliği içinde ve ortak amaçlar için çalışabilmesi için gerekli olan uyumun sağlanabilmesi için işgörenlerin davranışlarını şekillendiren, çalışanları ortak bir amaç doğrultusunda belirli hedeflere yönelten değerler bütünüdür (Campbell, 2004). Mintzberg kültürün, inanç ve değerleri olan bir organizasyonun ruhu olduğunu ve tüm bunların nasıl ortaya çıktığını belirtmektedir (Khalid, R.Madhakomala, \& Purwana, 2020). Denison ve Neale (1999), örgüt kültürünü bir örgütün 
yönetim sistemini oluşturan temel değerler, inançlar ve ilkeler olarak ortaya koymakta ve bu temel ilkeleri geliştiren uygulama ve davranışların örgüt kültürü olarak örgüt çalışanları için anlamlı olduğunu belirtmektedir. Cameron ve Quinn'e (2006) göre örgüt kültürü; değer yargıları, varsayımlar ve yorumlamalarla ifade edildiğine ve bu unsurlar, bazı ortak hususlar yardımıyla düzenlenebileceğine göre kültür tipleriyle ilgili bir model yaratılabilir. Araştırmacıların çalışmalarının temelini oluşturan "Rekabetçi Değerler Modeli” (Competing Values Framework), örgüt çalışmalarının önemli modellerinden biri olarak kabul edilmektedir.

\section{2. Örgütsel Çeviklik}

Örgütsel çeviklik, bir işletmenin değişime uyum sağlama veya değişime tepki verme kabiliyetidir. Ayrıca, işletmelerin uyumluluk ve yeniden düzenleme yeteneği, sürekli ve öngörülemeyen değişiklikler içeren bir ortamda hayatta kalma ve gelişme kabiliyetidir (Akkaya \& Tabak, 2018) Goldman, çevikliğin değişime ve belirsizliğe etkin bir karşılık olduğunu ifade eder (Nafei, 2016). Dinamik ve değişen işletme çevresini yönetmek ve hayatta kalabilmek için işletmeler acısından rekabetin artık lokal değil global olması, gelişen teknoloji, hızlı değişen çevre ve bunun getirdiği imkanlarla tüketiciyi memnun etmesi, işletmelerin ve çevik olmasını kaçınılmaz kılmaktadır. Olbert, Prodoehl ve Worley (2017), örgütsel çevikliğin bir örgütün verimlilik üstünlüğü sonucu ortaya çıkan sürekli değişikliklere hızlı, etkin ve uzun süreli uyum sağlama kabiliyeti olduğunu belirtmektedir.

\subsection{Firma Performansı}

\section{4. Örgüt Kültürü, Örgütsel Çeviklik ve Firma Performansı Arasındaki İlişkiler Üzerine Yapılan Araştırmalar}

Araştırmanın dayandı̆̆ı model Cameron ve Quinn (1985)'nin çalışmasıdır. Bu çalışmada, örgütsel kültürlerin uyumu, gücü ve türü ile örgütsel etkililik arasındaki ilişkiyi araştırmaktadır. Literatür, bir organizasyonun kültürünün gücü ve uyumunun yüksek performans seviyeleriyle nadiren ilişkilendirildiği önermelerle doludur. 334 yüksek eğitim kurumunun kültürlerinin karşılaştırılması, uyumlu kültürlere sahip olanlar ile uyumsuz kültürlere sahip olanlar arasında örgütsel etkinlik açısından anlamlı bir fark olmadığını ortaya koymuştur. Benzer şekilde, güçlü kültürlere sahip kurumlar, zayıf kültürlere sahip kurumlardan daha etkili değildir. Bununla birlikte çalışma, kurumların sahip olduğu kültür türünün -klan, adhokrasi, hiyerarşi veya Pazar- etkililik 
ve diğer örgütsel niteliklerle önemli bir ilişkiye sahip olduğuna işaret etti. Etkililiği açıklamada kültürel tipin uyum veya güçten daha önemli olduğu ortaya çımıştır.

Rekabetçi değerler modeli olarak da bilinen Cameron ve Quinn modelinin içinde yer alan dört kültür tipinin oluşumunda iki önemli boyuttan yararlanılmaktadır. Modelin ilk boyutu, esneklik odaklı olmak ile kontrol odaklı olmak arasında yer almaktadır. Esneklik odaklı olmak, yenilikçi olmak ve değişikliklere uyumlu olmak anlamında ifade edilirken; kontrol odaklı olmak tahmin edilebilirlik olarak ifade edilmektedir. Modelin diğer boyutu ise, içsel süreçlere odaklı olmak ile dışsal süreçlere odaklı olmak arasında yer almaktadır. İçsel süreçlere odaklı olmak, çalışan uyumu, çalışan birliği, içsel süreçlere yönelme olarak kabul edilirken; dışsal süreçlere yönelik olmak hedefleri gerçekleştirme, farklılaşma ve rekabete yönelme olarak kabul edilmektedir.

Örgüt kültürü ile örgütsel çeviklik arasındaki ilişki, Khalid ve Purwana'nın (2020) yaptığ1 araştırma ile açıklanabilir. Bu makale, oldukça yüksek rekabetçi bir pazarda, liderliği ve örgüt kültürünü güçlendirerek rekabet gücüne ulaşmada örgütsel çevikliğin önemini ele almaktadır. Endonezya'daki Küçük ve Orta Ölçekli İşletmelerde girişimci liderliğin, örgüt kültürünün aracılık ettiği örgütsel çeviklik üzerindeki etkisini incelemeyi amaçlamaktadır. Araştırmanın örneklemini Endonezya'nın Doğu Jakarta kentindeki Endüstri Köyü merkezinden toplam 200 çalışan oluşturmaktadır. Bulgular, sırasıyla girişimci liderliğin ve örgüt kültürünün örgütsel çeviklik üzerinde olumlu ve anlamlı doğrudan etkilere sahip olduğunu göstermektedir. Ayrıca bulguların, örgütsel çevikliği teşvik etmek ve ticari faydalar elde etmek için KOBİ girişimcilerine uygun liderlik ve örgüt kültürü için kılavuzluk edebileceği belirtilmiştir. Araştırmanın sınırlılığı olarak, yalnızca giyim sanayi sektöründen alınmış olmasıdır. Yeni çalışmalar için farklı KOBİ sektörlerine bakılması önerilmektedir. Ayrıca bu çalışmada tartışılan bağımsız değişkenlerin girişimci liderlik ve örgüt kültürü ile sınırlandırıldığı, örgütsel çevikliği etkileyebilecek daha fazla değişkeni incelemek için daha fazla araştırma yapılması önerilmektedir.

Örgütsel çeviklik ile firma performansı arasındaki ilişki Uyeno (2019)'nun çalışması ile kurulabilir. Bu makalede Company Culture 500 veri setini dikkate alarak örgüt kültürünün 9 alt boyutunun firma performansına olan etkisi incelenmiştir. Çeviklik, bu alt boyutlardan biridir. Diğer kültür alt boyutları ise (iş birliği, müşteri odaklılık, çeşitlilik, uygulama, yenilik, bütünlük performansı ve saygı). Firma performansı olarak hisse senedi değeri ve aktif karlılık ele alınmıştır. Firma sektörleri olarak finans, teknoloji, imalat ile medya ve iletişim alınmış ve çevikliğin 
teknoloji firmaları üzerinde etkisi çalışan memnuniyeti açısından tespit edilmiştir. Fakat çevikliğin, teknoloji, finans ve imalat sektöründeki firmaların hisse senedi değerleri üzerinde etkisi tespit edilememiştir.

$\mathrm{Bu}$ araştırmanın modelini oluşturan bir diğer ilişki örgüt kültürü ve firma performansı arasındaki ilişkidir. Bunun için Yılmaz vd. (2005)'nin araştırması ele alınmıştır. Bu araştırmada, kolektivizm ve güç mesafesi olan iki toplumsal kültür faktörünün, firma düzeyindeki yansımaları ve kültürel gücün organizasyonlarda müşteri ve öğrenme odaklı değer sistemlerinin gelişimi üzerindeki etkileri incelenmiştir. Veriler, Kocaeli sanayi bölgesinde bulunan 134 imalat firmasından üst düzey yöneticiler ve en az beş çalışan ile yüz yüze görüşmeler yoluyla 1349 kişiden toplanmıştır. Çalışmanın sonucunda, müşteri ve öğrenme odaklı bir organizasyonel değer sisteminin, uygun toplumsal kültür faktörleri ile tamamlandığında ve güçlü bir organizasyon kültürü ile desteklendiğinde, firma performansını geliştirme ve iyileştirme olasılığının daha yüksek olduğu görülmüştür. Kullanılan ölçek ağırlıklı olarak Denison'dan olacak şekilde farklı araştırmacılardan yola çıkarak oluşturulmuştur.

\subsection{Araştırmanın Hipotezleri, Soruları ve Araştırma Modeli}

Araştırma kapsamında aşağıdaki hipotezler oluşturulmuştur.

$\mathrm{H}_{1}$ : Klan kültürünün firma performansına etkisinde, örgütsel çevikliğin aracılık rolü vardır.

$\mathrm{H}_{1 \mathrm{a}}$ : Klan kültürü örgütsel çevikliği etkiler.

$\mathrm{H}_{1 \mathrm{~b}}$ : Örgütsel çeviklik firma performansını etkiler.

$\mathrm{H}_{1 \mathrm{c}}$ : Klan kültürü firma performansını etkiler.

$\mathrm{H}_{2}$ : Adhokrasi kültürünün firma performansına etkisinde, örgütsel çevikliğin aracılık rolü vardır.

$\mathrm{H}_{2 \mathrm{a}}$ : Adhokrasi kültürü örgütsel çevikliği etkiler.

$\mathrm{H}_{2 \mathrm{~b}}$ : Örgütsel çeviklik firma performansını etkiler.

$\mathrm{H}_{2 \mathrm{c}}$ : Adhokrasi kültürü firma performansını etkiler.

$\mathrm{H}_{3}$ : Hiyerarşi kültürünün firma performansına etkisinde, örgütsel çevikliğin aracılık rolü vardır.

$\mathrm{H}_{3 \mathrm{a}}$ : Hiyerarşi kültürü örgütsel çevikliği etkiler.

$\mathrm{H}_{3 \mathrm{~b}}$ : Örgütsel çeviklik firma performansını etkiler.

$\mathrm{H}_{3 \mathrm{c}}$ : Hiyerarşi kültürü firma performansını etkiler. 
$\mathrm{H}_{4}$ : Pazar kültürünün firma performansına etkisinde, örgütsel çevikliğin aracılık rolü vardır.

$\mathrm{H}_{4 \mathrm{a}}$ : Pazar kültürü örgütsel çevikliği etkiler.

$\mathrm{H}_{4 \mathrm{~b}}$ : Örgütsel çeviklik firma performansını etkiler.

$\mathrm{H}_{4 \mathrm{c}}$ : Pazar kültürü firma performansını etkiler.

Hipotezlere ek olarak araştırma kapsamında belirlenen sorular şu şekildedir:

1- Araştırmaya katılanların örgüt kültürü algıları, demografik özelliklere göre anlamlı farkl1lık gösterir mi?

2- Araştırmaya katılanların örgütsel çeviklik algıları, demografik özelliklere göre anlamlı farkl1lık gösterir mi?

3- Araştırmaya katılanların firma performansı algıları, demografik özelliklere göre anlamlı farklılık gösterir mi?

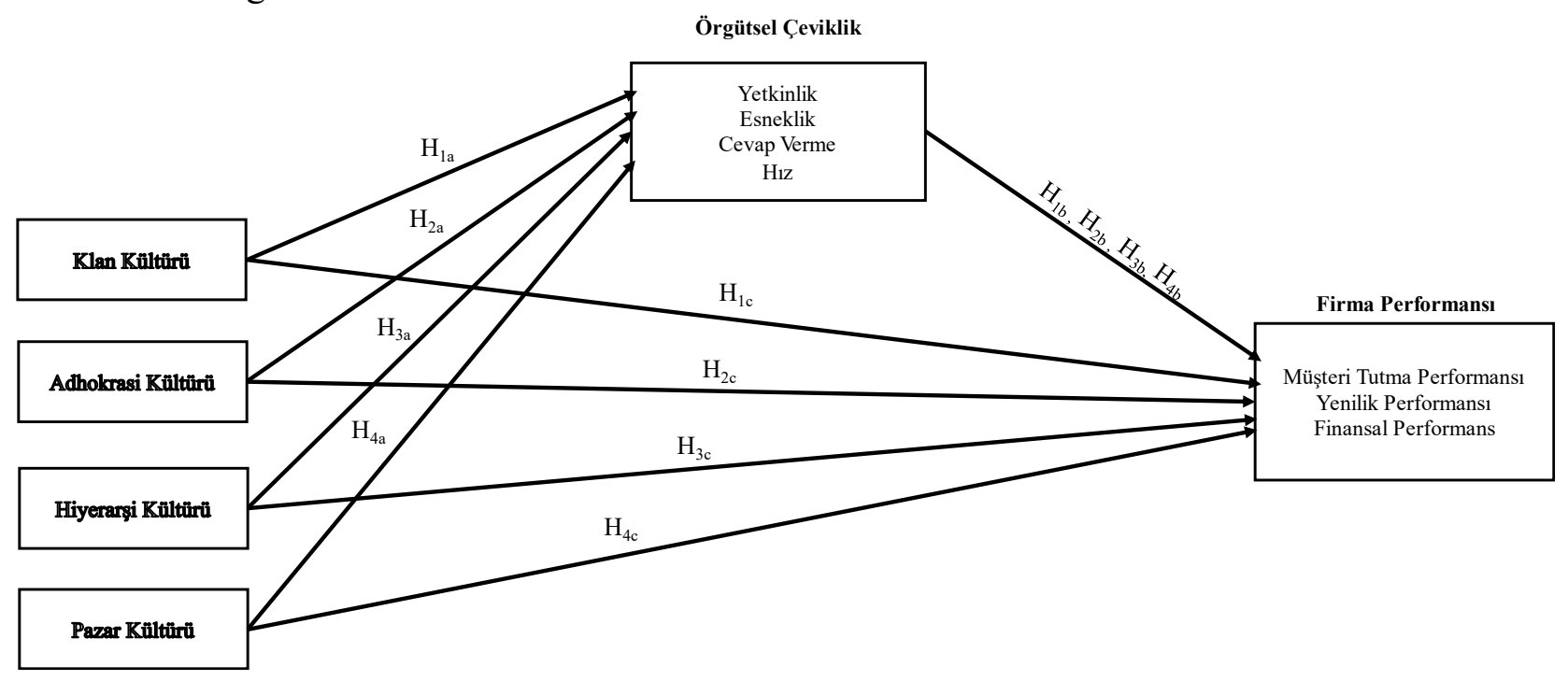

Hipotezler kapsamında araştırma modeli Şekil 1'de görülmektedir.

\section{Şekil 1: Araştırma Modeli}

\section{Araştirma Yöntemi}

\subsection{Evren ve Örneklem}

Araştırmanın evrenini İstanbul, Ankara, İzmir, Tekirdağ, Kocaeli ve Zonguldak illerindeki İmalat, Hizmet, IT, Perakende ve Tarım sektörlerine ait firma çalışanları oluşturmaktadır. Özellikle bu 
sektörlerde çalışanların seçilme sebebi, farklı örgüt kültürleri ile firmanın faaliyet yaşı ve firma çalışan sayılarının farklı yapılara sahip oldukları varsayımından kaynaklanmaktadır. Anket verileri, tesadüfî olmayan kolayda örnekleme yöntemi kullanılarak, çevrimiçi anket yöntemiyle toplanmıştır. Bu kapsamda, 600 kişiye araştırma anketinin bulunduğu elektronik form bağlantısı gönderilmiş, 140 kişiden geri dönüş alınmış ve (cevaplama oranı: \%23) araştırmanın örneklemini oluşturmuştur.

\section{2. Ölçme Araçları}

Araştırmada kullanılan soru formunun dört bölümünde cinsiyet, yaş, medeni durum, eğitim düzeyi, çalışma şekli, işyeri kıdemi, yönetici olup olmadığı, firmanın bulunduğu sektör, firmanın faaliyet yaşı, çalışan sayısına göre firmanın büyüklüğü bilgilerini içeren demografik sorular, ikinci bölümde örgütün kültür tipini belirlemeye yönelik örgüt kültürü ölçeği, üçüncü bölümde örgütün çeviklik düzeyini algılamaya yönelik örgütsel çeviklik ölçeği, son bölümde ise firmanın müşteri tutma, yenilik ve finansal performansları açısından firma performans algısının ölçüldüğü maddeler yer almaktadir.

\section{Örgüt Kültürü Ölçeği}

Örgüt kültürü ölçeği, Cameron ve Quinn'in modeli esas alınarak Deshpande vd. (1993) tarafından geliştirilmiş ve Karakılıç (2019) tarafından Türkçe uyarlaması ve geçerlilik çalışması yapılmıştır. Toplam 16 ifadeden oluşan ölçekteki maddeler 5'li Likert tipinde derecelendirilerek "1-Kesinlikle Katılmıyorum" ile "5-Kesinlikle Katılıyorum" arasında puanlanmıştır. Ölçek, Klan kültürü, Adokrasi kültürü, Hiyerarşi kültürü ve Pazar kültürü olarak dört boyuttan oluşmaktadır.

\section{Örgütsel Çeviklik Ölçeği}

Örgütsel çeviklik ölçeği, Sharifi ve Zhang (1999) tarafından geliştirilmiş ve Akkaya vd. (2018) tarafından Türkçeye uyarlanarak geçerlilik çalışması yapılmıştır. Toplam 17 ifadeden oluşan ölçekteki maddeler 5'li Likert tipinde derecelendirilerek "1-Hiçbir Zaman" ile "5-Her Zaman" arasında puanlanmıştır. Ölçek, Yetkinlik, Esneklik, Cevap Verme ve Hız olarak dört boyuttan oluşmaktadır.

\section{Firma Performansı Ölçeği}

Firma performansını ölçmek üzere 3 farklı değişken ele dikkate alınmıştır. Bunlar müşteri tutma, yenilik ve finansal performanslardır. Bu kapsamda her bir performans için ayrı ölçekler 
kullanılmaktadır. Müşteri tutma ölçeği Shin vd. (2015) tarafından geliştirilmiş ve Uğurlu vd. (2019) tarafından geçerlilik çalışması yapılmıştır. Ölçek 3 ifadeden oluşmaktadır. Yenilik performansı ölçeği Antoncic ve Hisrich (2001), Neely ve Hii (1998) ile Hagedoorn ve Cloodt (2003)'un, çalışmalarından birleştirilerek oluşturulmuş, Bulut vd. (2009) tarafından Türkçe'ye uyarlanmıştır. Ölçek 7 ifadeden oluşmaktadır. Bu iki ölçekteki maddeler 5'li Likert tipinde derecelendirilerek "1-Kesinlikle Katılmıyorum" ile "5-Kesinlikle Katıliyorum" arasinda puanlanmıştır. Finansal performans ölçeği ise Denison (2002) ve Yılmaz, Alpkan ve Ergün (2005)'in çalışmalarından birleştirilerek oluşturulmuş, Bulut vd. (2009) tarafından Türkçe'ye uyarlanmıştır. Ölçekte 3 madde yer almakta olup, maddeler 5'li Likert tipinde derecelendirilerek “1-Yetersiz” ile "5-Yüksek” arasında puanlanmıştır.

\section{3. Ölçeklerin Geçerlilik ve Faktör Analizleri}

Ölçeklerin Doğrulayıcı Faktör Analizleri yapılmıştır. Örgüt Kültürü ölçeği için toplam 4 faktörlü bir yapı incelenmiştir. İncelenen yapıda Klan boyutu için 4, Adhokrasi boyutu için 4, Hiyerarşi boyutu için 4 ve Pazar boyutu için 4 madde ölçekte yer almaktadır. Doğrulayıcı Faktör Analizi sonucunda model uyum kriterleri incelenmiş ve istenilen sınırlarda olmadı̆̆ından dolayı modifikasyon indekslerine bakılmıştır. Bunun sonucunda öncelikle Pazar1 maddesi, ölçeğin Pazar Kültürü boyutunu anlamlı derecede etkilemediği, Pazar3, Klan3 ve Adhokrasi3 maddelerinin ise diğer faktörler altındaki değişkenlerle bir kovaryans bağlantısına sahip olduğu için ölçekten çıkartılarak analiz yapılmıştır. Sonuçlar Tablo 1'de listelenmiştir.

Tablo 1: Örgüt Kültürü Ölçeğinin Doğrulayıcı Faktör Analizi Katsayıları

\begin{tabular}{lllccccc}
\hline Madde & Path & Faktör & $\boldsymbol{\beta}_{0}$ & $\boldsymbol{\beta}_{1}$ & S.E. & C.R. & P \\
\hline Klan4 & $<---$ & Klan & 0,766 & 1 & & & \\
Klan2 & $<---$ & Klan & 0,807 & 0,95 & 0,103 & 9,207 & $<0,001$ \\
Klan1 & $<---$ & Klan & 0,611 & 0,61 & 0,088 & 6,92 & $<0,001$ \\
Adhokrasi4 & $<---$ & Adhokrasi & 0,911 & 1 & & & \\
Adhokrasi2 & $<---$ & Adhokrasi & 0,832 & 0,99 & 0,081 & 12,239 & $<0,001$ \\
Adhokrasi1 & $<---$ & Adhokrasi & 0,383 & 0,48 & 0,107 & 4,516 & $<0,001$ \\
Hiyerarsi4 & $<---$ & Hiyerarşi & 0,742 & 1 & & & \\
Hiyerarsi3 & $<---$ & Hiyerarşi & 0,611 & 0,93 & 0,136 & 6,838 & $<0,001$
\end{tabular}




$\begin{array}{lclccccc}\text { Hiyerarsi2 } & <--- & \text { Hiyerarşi } & 0,419 & 0,6 & 0,128 & 4,656 & <0,001 \\ \text { Hiyerarsi1 } & <--- & \text { Hiyerarşi } & 0,307 & 0,48 & 0,142 & 3,392 & <0,001 \\ \text { Pazar4 } & <--- & \text { Pazar } & 0,668 & 1 & & & \\ \text { Pazar2 } & <--- & \text { Pazar } & 0,205 & 0,26 & 0,104 & 2,512 & 0,012\end{array}$

$\boldsymbol{\beta}_{0}$ : Standart Yol Katsayıları, $\boldsymbol{\beta}_{1}$ : Standart Olmayan Yol Katsayıları

Örgüt Kültürü ölçeğindeki Pazar1, Pazar3, Klan3 ve Adhokrasi3 maddeleri ölçekten çıkartıldığında elde edilen çözüm ile $\mathrm{CMIN}=137,763, \mathrm{DF}=47, \mathrm{p}<0,001, \mathrm{CMIN} / \mathrm{DF}=2,931$, RMSEA $=0,118, \mathrm{NFI}=0,818, \mathrm{CFI}=0,868, \mathrm{GFI}=0,855$ olarak, kabul edilebilir sınırlar içerisinde bulunmuştur. Bu da modelin uyumlu olduğu anlamına gelmektedir. Örgüt Kültürü ölçeğine ait standartlaştırılmış yol katsayıları Şekil 2'de yer almaktadır.

\section{Şekil 2: Örgüt Kültürü Ölçeğinin Standartlaştırılmış Yol Katsayıları}

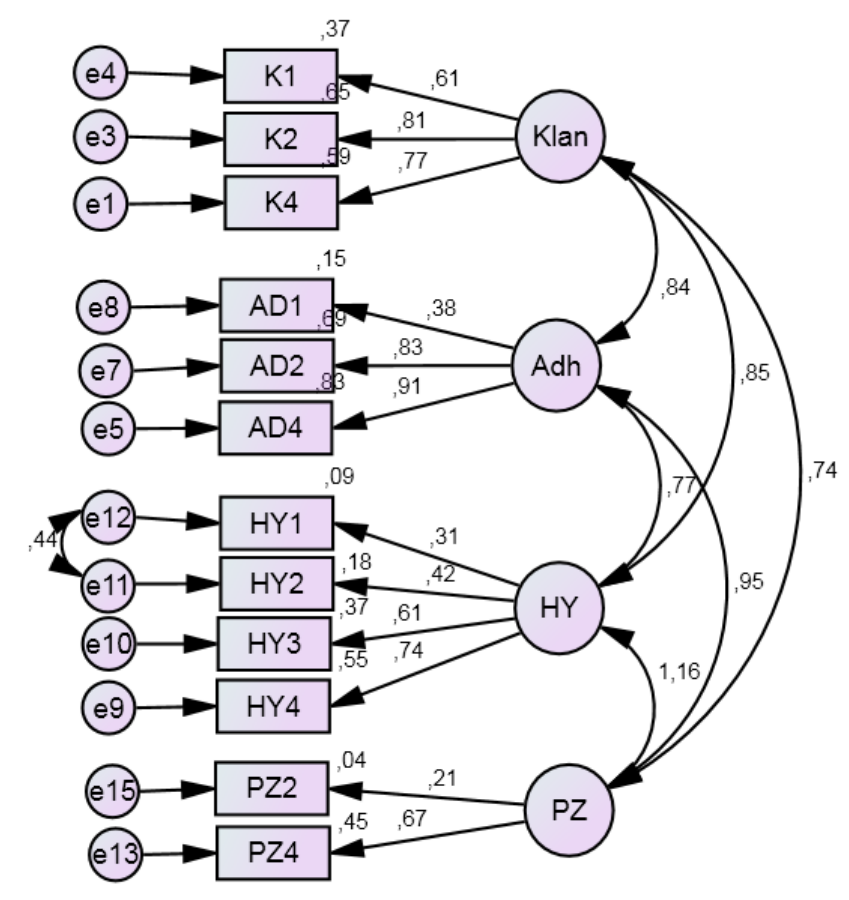

$\mathrm{CMIN}=137,763 ; \mathrm{DF}=47 ; \mathrm{p}=, 000 ; \mathrm{CMIN} / \mathrm{DF}=2,931 ; \mathrm{GFI}=, 855 ; \mathrm{NFI}=, 818 ; \mathrm{CFI}=, 868 ; \mathrm{RMSEA}=, 118$

Örgütsel Çeviklik ölçeği için toplam 4 faktörlü bir yapı incelenmiştir. İncelenen yapıda Yetkinlik boyutu için 8, Esneklik boyutu için 3, Cevap Verme boyutu için 3 ve Hız boyutu için 3 madde 
ölçekte yer almaktadır. Doğrulayıcı Faktör Analizi sonucunda model uyum kriterleri incelenmiş ve istenilen sınırlarda olmadığından dolayı modifikasyon indekslerine bakılmıştır. Bunun sonucunda, ölçeğin Yetkinlik5, Yetkinlik7, Esneklik2, CevapVerme2 ve Hız3 maddelerinin ise diğer faktörler altındaki değişkenlerle bir kovaryans bağlantısına sahip olduğu için ölçekten çıkartılarak analiz yapılmıştır. Sonuçlar Tablo 2’de listelenmiştir.

Tablo 2: Örgütsel Çeviklik Ölçeğinin Doğrulayıcı Faktör Analizi Katsayıları

\begin{tabular}{lllccccc}
\hline Madde & Path & Faktör & $\boldsymbol{\beta}_{\mathbf{0}}$ & $\boldsymbol{\beta}_{1}$ & S.E. & C.R. & P \\
\hline AgileYetkin8 & $<---$ & Yetkinlik & 0,685 & 1 & & & \\
AgileYetkin6 & $<---$ & Yetkinlik & 0,723 & 0,94 & 0,127 & 7,386 & $<0,001$ \\
AgileYetkin3 & $<---$ & Yetkinlik & 0,733 & 0,8 & 0,107 & 7,472 & $<0,001$ \\
AgileYetkin2 & $<---$ & Yetkinlik & 0,698 & 0,818 & 0,114 & 7,151 & $<0,001$ \\
AgileEsnek3 & $<---$ & Esneklik & 0,852 & 1 & & & $<0,001$ \\
AgileEsnek1 & $<---$ & Esneklik & 0,748 & 0,886 & 0,093 & 9,506 & $<0,001$ \\
AgileCevap3 & $<---$ & Cevap Verme & 0,777 & 1 & & & \\
AgileHiz2 & $<---$ & Hiz & 0,764 & 1 & & & \\
AgileCevap1 & $<---$ & Cevap Verme & 0,821 & 1,062 & 0,1 & 10,613 & $<0,001$ \\
AgileYetkin4 & $<---$ & Yetkinlik & 0,342 & 0,406 & 0,12 & 3,397 & $<0,001$ \\
AgileHiz1 & $<---$ & Hiz & 0,801 & 1,012 & 0,125 & 8,094 & $<0,001$ \\
AgileYetkin1 & $<---$ & Yetkinlik & 0,670 & 0,896 & 0,13 & 6,886 & $<0,001$ \\
\hline
\end{tabular}

$\boldsymbol{\beta}_{0}:$ Standart Yol Katsayıları, $\boldsymbol{\beta}_{\mathbf{1}}$ : Standart Olmayan Yol Katsayıları

Örgütsel çeviklik ölçeğindeki Yetkinlik5, Yetkinlik7, Esneklik2, CevapVerme2 ve Hız3 maddeleri ölçekten çıkartıldığında elde edilen çözüm ile $\mathrm{CMIN}=107,333,763, \quad \mathrm{DF}=46, \quad \mathrm{p}<0,001$, $\mathrm{CMIN} / \mathrm{DF}=2,333, \mathrm{RMSEA}=0,098, \mathrm{NFI}=0,883, \mathrm{CFI}=0,928, \mathrm{GFI}=0,899$ olarak, kabul edilebilir sınırlar içerisinde bulunmuştur. Bu da modelin uyumlu olduğu anlamına gelmektedir. Örgütsel Çeviklik ölçeğine ait standartlaştırılmış yol katsayıları Şekil 3'de yer almaktadır.

\section{Şekil 3: Örgütsel Çeviklik Ölçeğinin Standartlaştırılmış Yol Katsayıları}




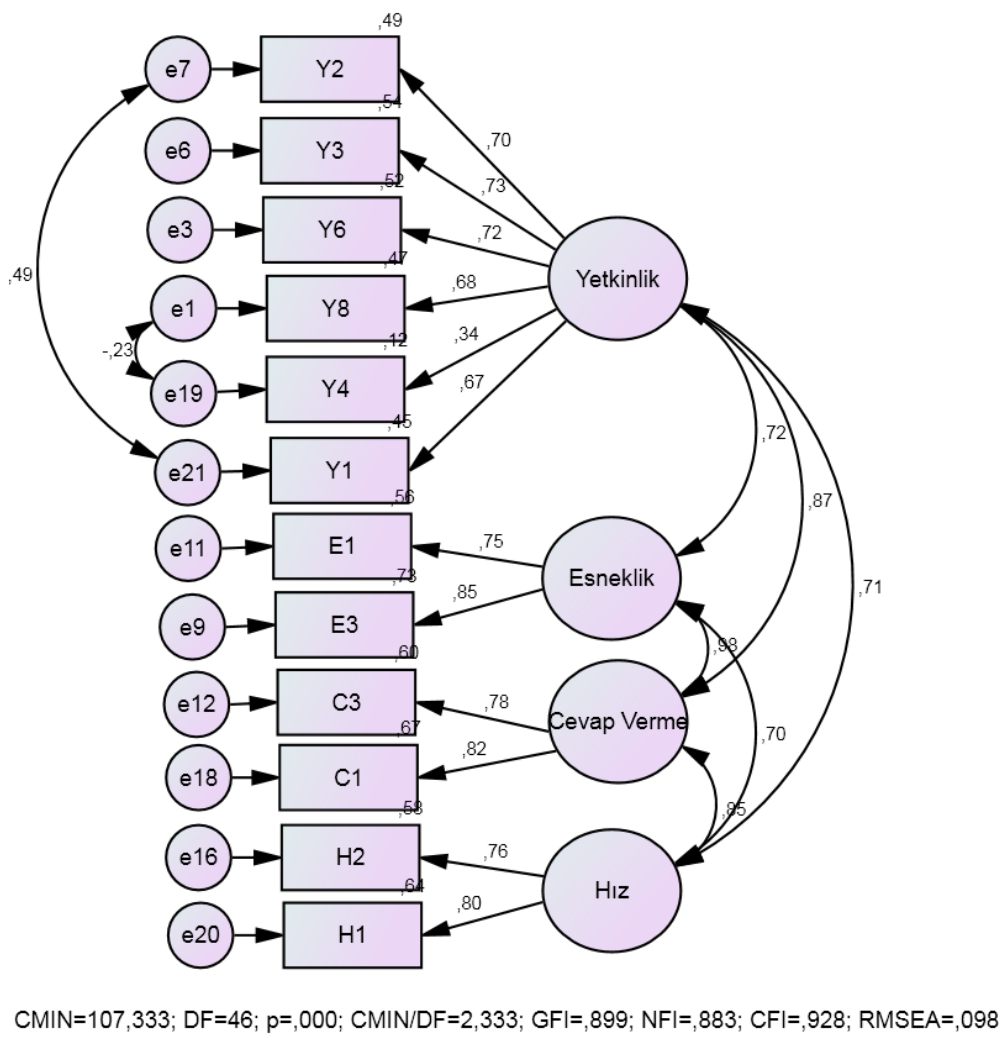

Firma Performansı ölçeği için toplam 3 faktörlü bir yapı incelenmiştir. İncelenen yapıda Müşteri Tutma için 3, Yenilik boyutu için 7 ve Finansal Performans boyutu için 3 madde ölçekte yer almaktadır (EK-1). Doğrulayıcı Faktör Analizi sonucunda model uyum kriterleri incelenmiş ve istenilen sınırlarda olmadığından dolayı modifikasyon indekslerine bakılmıştır. Bunun sonucunda Yenilik7 diğer faktörler altındaki değişkenlerle bir kovaryans bağlantısına sahip olduğu için ölçekten çıkartılarak analiz yapılmıştır. Sonuçlar Tablo 3'de listelenmiştir.

Tablo 3: Firma Performansı Ölçeğinin Doğrulayıcı Faktör Analizi Katsayıları

\begin{tabular}{lclccccc}
\hline Madde & Path & Faktör & $\boldsymbol{\beta}_{\mathbf{0}}$ & $\boldsymbol{\beta}_{1}$ & S.E. & C.R. & P \\
\hline FirPerMusteri3 & $<---$ & MusteriTutma & 0,649 & 1 & & & \\
FirPerMusteri2 & $<---$ & MusteriTutma & 0,889 & 1,388 & 0,174 & 7,976 & $<0,001$ \\
FirPerMusteri1 & $<---$ & MusteriTutma & 0,835 & 1,409 & 0,178 & 7,906 & $<0,001$ \\
FirPerYenilik3 & $<---$ & Yenilik & 0,881 & 1 & & & \\
FirPerYenilik2 & $<---$ & Yenilik & 0,896 & 1,014 & 0,066 & 15,314 & $<0,001$ \\
FirPerYenilik1 & $<---$ & Yenilik & 0,85 & 0,992 & 0,072 & 13,74 & $<0,001$
\end{tabular}




\begin{tabular}{lclccccc} 
FinansalPer3 & $<---$ & Finansal & 0,999 & 1 & & & \\
FinansalPer2 & $<---$ & Finansal & 0,931 & 0,933 & 0,034 & 27,174 & $<0,001$ \\
FinansalPer1 & $<---$ & Finansal & 0,911 & 0,936 & 0,039 & 24,224 & $<0,001$ \\
FirPerYenilik4 & $<---$ & Yenilik & 0,866 & 0,907 & 0,064 & 14,262 & $<0,001$ \\
FirPerYenilik5 & $<---$ & Yenilik & 0,833 & 0,903 & 0,068 & 13,214 & $<0,001$ \\
FirPerYenilik6 & $<---$ & Yenilik & 0,675 & 0,945 & 0,101 & 9,34 & $<0,001$ \\
\hline
\end{tabular}

$\boldsymbol{\beta}_{0}$ : Standart Yol Katsayıları, $\boldsymbol{\beta}_{1}$ : Standart Olmayan Yol Katsayıları

Firma Performansı ölçeğindeki Yenilik7 maddesi ölçekten çıkartıldığında elde edilen çözüm ile $\mathrm{CMIN}=87,367, \mathrm{DF}=51, \mathrm{p}<0,001, \mathrm{CMIN} / \mathrm{DF}=1,713$, RMSEA=0,072, NFI=0,941, CFI=0,974, $\mathrm{GFI}=0,904$ olarak, kabul edilebilir sınırlar içerisinde bulunmuştur. Bu da modelin iyi düzeyde uyumlu olduğu anlamına gelmektedir. Firma Performansı ölçeğine ait standartlaştırılmış yol katsayıları Şekil 4'de yer almaktadır.

\section{Şekil 4: Firma Performansı Ölçeğinin Standartlaştırılmış Yol Katsayıları}

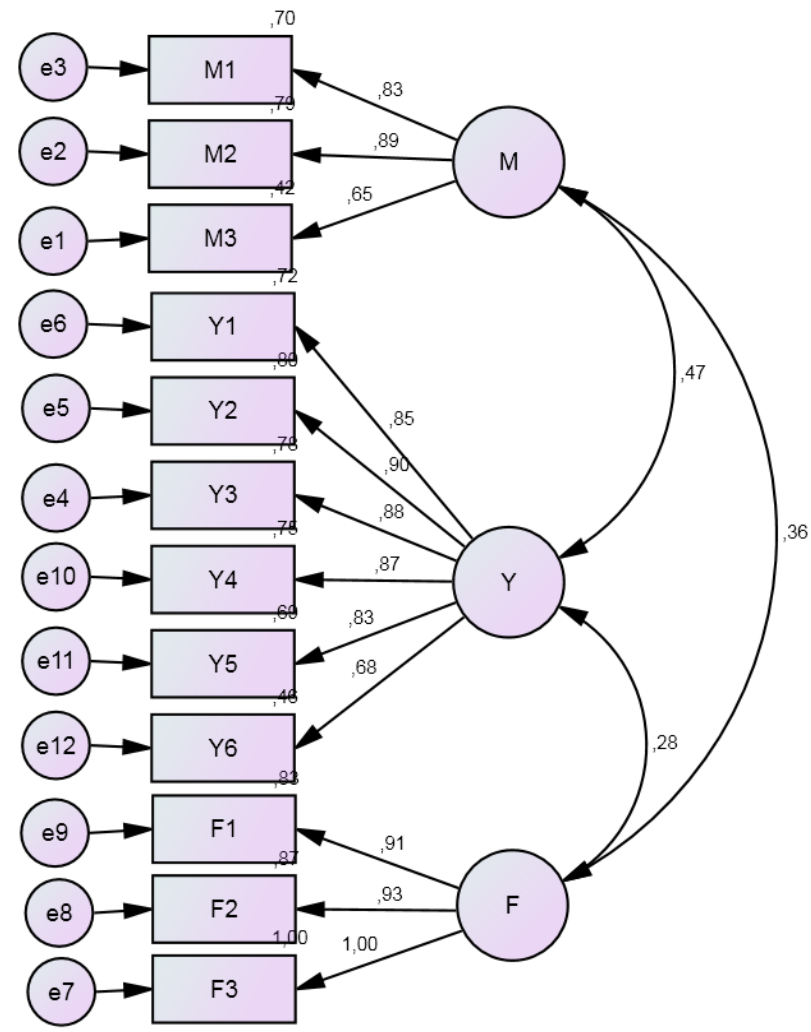

$\mathrm{CMIN}=87,367 ; \mathrm{DF}=51 ; \mathrm{p}=, 001 ; \mathrm{CMIN} / \mathrm{DF}=1,713 ; \mathrm{GFI}=, 904 ; \mathrm{NFI}=, 941 ; \mathrm{CFI}=, 974 ; \mathrm{RMSEA}=, 072$ 


\section{4. Ölçeklerin Güvenilirliği}

Ölçeklerin güvenilirlik analizi için Cronbach’s Alpha değerine bakılarak, Örgüt Kültür Ölçeği 0,851, Örgütsel Çeviklik Ölçeği 0,902 ve Firma Performansı ölçeği 0,896 olarak tespit edilmiştir. Her üç ölçeğin de güvenilir olduğu söylenebilir.

\section{Bulgular Ve Tartışma}

Bulguların analizi için SPSS ve AMOS programları kullanılmıştır. Demografik özellikler incelendiğinde çalışanların \% 40,7'si kadın, \% 59,3’ü erkektir. Yaş grupları \% 73,6 ile 36-55 aralığında yoğunlaşmış olup, ortalama yaş 42,57 olmuştur. Medeni duruma göre \% 72,3 ile çoğunluğu evliler oluşturmaktadır. Eğitim düzeyleri açısından, lisans ve lisans üstü grubundaki çalışanlar toplamın \% 92,1 gibi yüksek bir kısmını oluşturmaktadır. Çalışma şekillerine göre \%92,9’luk gibi baskın bir oranla beyaz yakalı çalışanların görüşleri elde edilmiştir. İşyeri kıdeminde \% 39,3 oranını ilk 5 yıllık çalışanlar oluşturmakta olup, ortalama kıdem yılı 10,56'dır. Çalışanların ise \% 60,7'sini yönetici konumunda olanlar oluşturmaktadır. Ayrıca, araştırmaya katılanların \% 56,4’ü İmalat sektöründe, \% 55’i 20 yılın üzerinde yaşa sahip bir firmada, \% 53,6 ise çalışan sayısı 250'nin üzerinde olan büyük ölçekli firmalarda çalışmaktadır. Katılımcıların demografik özellikleri Tablo 4'de listelenmiştir.

Tablo 4: Demografik Özelliklerin Dağılımı

\begin{tabular}{|c|c|c|c|c|c|c|c|}
\hline \multicolumn{2}{|c|}{ Demografik Değişken } & \multirow{2}{*}{$\begin{array}{c}\text { Sayı } \\
83\end{array}$} & Yüzde & \multicolumn{2}{|c|}{ Demografik Değişken } & \multirow{2}{*}{$\frac{\text { Sayı }}{41}$} & Yüzde \\
\hline \multirow[t]{2}{*}{ Cinsiyet } & Erkek & & 59,3 & Firmanın Sektörü & Hizmet & & 29,3 \\
\hline & Kadın & 57 & 40,7 & & IT & 12 & 8,6 \\
\hline Yaş & $26-35$ & 34 & 24,3 & & İmalat & 79 & 56,4 \\
\hline \multirow[t]{4}{*}{ Grupları } & $36-45$ & 50 & 35,7 & & Perakende & 7 & 5 \\
\hline & $46-55$ & 53 & 37,9 & & Tarım & 1 & 0,7 \\
\hline & 55 'den & 3 & 2,1 & Yönetici mi? & Evet & 85 & 60,7 \\
\hline & Büyük & & & & & & \\
\hline Medeni & Evli & 101 & 72,1 & & Hayır & 55 & 39,3 \\
\hline Durum & Bekâr & 39 & 27,9 & & $0-5 Y_{11}$ & 8 & 5,7 \\
\hline
\end{tabular}




\begin{tabular}{|c|c|c|c|c|c|c|c|}
\hline Eğitim & Lise & 11 & 7,9 & \multirow{7}{*}{$\begin{array}{l}\text { Firmanın Faaliyet } \\
\text { Yaşı }\end{array}$} & $6-10 Y_{1}$ & 24 & 17,1 \\
\hline \multirow[t]{2}{*}{ Düzeyi } & Lisans & 72 & 51,4 & & 11-20 Y1l & 31 & 22,1 \\
\hline & Lisansüstü & 57 & 40,7 & & 21-30 Y1l & 20 & 14,3 \\
\hline \multirow{3}{*}{$\begin{array}{l}\text { Çalışma } \\
\text { Şekli }\end{array}$} & Mavi Yakalı & 10 & 7,1 & & $31-50 \mathrm{Y} 11$ & 13 & 9,3 \\
\hline & Beyaz & 130 & 92,9 & & $51-90$ Y11 & 22 & 15,7 \\
\hline & Yakalı & & & & & & \\
\hline İşyeri & $0-5 Y_{11}$ & 55 & 39,3 & & 91 Yil ve Üzeri & 22 & 15,7 \\
\hline \multirow[t]{8}{*}{ Kidemi } & 6-10 Y1l & 29 & 20,7 & Firmanın & 10'dan Az & 16 & 11,4 \\
\hline & & & & Büyüklüğü & Çalışan & & \\
\hline & 11-15 Y1l & 16 & 11,4 & & 10-49 Çalışan & 20 & 14,3 \\
\hline & 16-20 Y1l & 16 & 11,4 & & 50-249 Çalışan & 29 & 20,7 \\
\hline & 21 Y1l ve & 24 & 17,1 & & 250-1999 & 29 & 20,7 \\
\hline & Üzeri & & & & Çalışan & & \\
\hline & & & & & 2000 ve Üzeri & 46 & 32,9 \\
\hline & & & & & Çalışan & & \\
\hline
\end{tabular}

\subsection{Betimsel İstatistikler}

$\mathrm{Bu}$ bölümde araştırmada kullanılan gizil değişkenlere ilişkin betimsel analiz sonuçlarına yer verilmiştir. Yapılan korelasyon analizi sonucunda; firma performansı boyutlarından finansal performans ile klan kültürü arasında anlamlı ilişki tespit edilmemiştir. Buna karşın, klan kültürü ile örgütsel çeviklik arasında pozitif yönlü ve anlamlı $(\mathrm{r}=0.54, \mathrm{p}<.01)$, klan kültürü ile firma performansı arasında pozitif yönlü ve anlamlı ( $\mathrm{r}=-0.48, \mathrm{p}<.01)$, adhokrasi kültürü ile örgütsel çeviklik arasında pozitif yönlü ve anlamlı $(\mathrm{r}=0.72, \mathrm{p}<.01)$, adhokrasi kültürü ile firma performansı arasında pozitif yönlü ve anlamlı $(\mathrm{r}=-0.52, \mathrm{p}<.01)$, hiyerarşi kültürü ile örgütsel çeviklik arasında pozitif yönlü ve anlamlı $(\mathrm{r}=0.49, \mathrm{p}<.01)$, hiyerarşi kültürü ile firma performansı arasında pozitif yönlü ve anlamlı $(\mathrm{r}=-0.43, \mathrm{p}<.01)$, pazar kültürü ile örgütsel çeviklik arasında pozitif yönlü ve anlamlı $(\mathrm{r}=0.53, \mathrm{p}<.01)$ ve Pazar kültürü ile firma performansı arasında pozitif yönlü ve anlamlı $(\mathrm{r}=-0.43, \mathrm{p}<.01$ ilişkiler olduğu tespit edilmiştir. Bunların yanında, firma çalışanlarının hem örgütsel çevikliği algıladıkları $(\overline{\mathrm{x}}=3.93)$ hem de firma performansı algısına sahip oldukları $(\overline{\mathrm{x}}=$ 3.81) görülmektedir. 


\subsection{Yapısal Eşitlik Modellemesi (YEM) Analizi}

Araştırma modeli kapsamında oluşturulan hipotezlerin test edilmesinde çoklu regresyon analizi yöntemi olan YEM tercih edilmiştir. Araştırma kapsamında oluşturulan hipotezleri test etmek amacıyla, araştırmanın bağımsız değişkenleri olan Klan, Adhokrasi, Hiyerarşi ve Pazar kültürü ile bağımlı değişkenler örgütsel çeviklik ve firma performansı arasında oluşturulan yapısal eşitlik modellemesine ait analiz sonuçları aşağıda yer almaktadır.

Ölçüm modeli kapsamında, analiz sonuçlarındaki tahminler incelendiğinde Klan kültürü, çeviklik ve firma performansı değişkenlerine ait elde edilen tüm katsayıların istatistiksel olarak anlamlı olduğu gözlemlenmiştir. Buna ait veriler Tablo 5'de listelenmiştir.

Tablo 5: Ölçüm Modeline Ait Yol Katsayıları ve Anlamlılık Düzeyleri (Klan Kültürü)

\begin{tabular}{|c|c|c|c|c|c|c|c|}
\hline Ölçüm Modeli & & & $\beta_{0}$ & $\beta_{1}$ & S.E. & C.R. & $\mathbf{P}$ \\
\hline Yetkinlik & <--- & Çeviklik & 0,85 & 0,922 & 0,157 & 5,859 & $<0,001$ \\
\hline Esneklik & $<---$ & Çeviklik & 0,88 & 1,31 & 0,168 & 7,799 & $<0,001$ \\
\hline CevapVerme & $<--$ & Çeviklik & 1,028 & 1,361 & 0,164 & 8,279 & $<0,001$ \\
\hline $\mathrm{H} 1 \mathrm{z}$ & $<--$ & Çeviklik & 0,831 & 1 & & & \\
\hline MusteriTutma & $<--$ & FirPerf & 0,694 & 1,279 & 0,352 & 3,635 & $<0,001$ \\
\hline Yenilik & $<--$ & FirPerf & 0,763 & 2,105 & 0,532 & 3,955 & $<0,001$ \\
\hline Finansal & $<---$ & FirPerf & 0,375 & 1 & & & \\
\hline Klan4 & $<---$ & Klan & 0,791 & 1 & & & \\
\hline Klan2 & $<--$ & Klan & 0,802 & 0,912 & 0,109 & 8,352 & $<0,001$ \\
\hline Klan1 & $<--$ & Klan & 0,579 & 0,556 & 0,088 & 6,342 & $<0,001$ \\
\hline AgileYetkin8 & $<--$ & Yetkinlik & 0,605 & 1 & & & \\
\hline AgileYetkin6 & $<--$ & Yetkinlik & 0,647 & 0,952 & 0,129 & 7,372 & $<0,001$ \\
\hline AgileYetkin3 & $<---$ & Yetkinlik & 0,71 & 0,878 & 0,133 & 6,595 & $<0,001$ \\
\hline AgileYetkin2 & $<--$ & Yetkinlik & 0,796 & 1,056 & 0,149 & 7,105 & $<0,001$ \\
\hline AgileEsnek3 & $<--$ & Esneklik & 0,875 & 1 & & & \\
\hline AgileEsnek1 & $<---$ & Esneklik & 0,728 & 0,84 & 0,093 & 9,007 & $<0,001$ \\
\hline AgileCevap3 & $<--$ & CevapVerme & 0,825 & 1 & & & \\
\hline AgileHiz2 & $<---$ & $\mathrm{H} 1 \mathrm{z}$ & 0,786 & 1 & & & \\
\hline
\end{tabular}




\begin{tabular}{lllccccc} 
AgileCevap1 & $<---$ & CevapVerme & 0,774 & 0,943 & 0,09 & 10,439 & $<0,001$ \\
AgileYetkin4 & $<---$ & Yetkinlik & 0,297 & 0,4 & 0,126 & 3,176 & 0,001 \\
AgileHiz1 & $<---$ & Hiz & 0,779 & 0,957 & 0,116 & 8,265 & $<0,001$ \\
AgileYetkin1 & $<---$ & Yetkinlik & 0,792 & 1,2 & 0,169 & 7,084 & $<0,001$ \\
FirPerMusteri3 & $<---$ & MusteriTutma & 0,671 & 1 & & & \\
FirPerMusteri2 & $<---$ & MusteriTutma & 0,866 & 1,308 & 0,157 & 8,333 & $<0,001$ \\
FirPerMusteri1 & $<---$ & MusteriTutma & 0,845 & 1,38 & 0,167 & 8,263 & $<0,001$ \\
FirPerYenilik3 & $<---$ & Yenilik & 0,868 & 1 & & & \\
FirPerYenilik2 & $<---$ & Yenilik & 0,843 & 0,966 & 0,062 & 15,649 & $<0,001$ \\
FirPerYenilik1 & $<---$ & Yenilik & 0,831 & 0,985 & 0,079 & 12,518 & $<0,001$ \\
FinansalPer3 & $<---$ & Finansal & 0,998 & 1 & & & \\
FinansalPer2 & $<---$ & Finansal & 0,931 & 0,935 & 0,034 & 27,191 & $<0,001$ \\
FinansalPer1 & $<---$ & Finansal & 0,912 & 0,937 & 0,039 & 24,242 & $<0,001$ \\
FirPerYenilik4 & $<---$ & Yenilik & 0,88 & 0,937 & 0,068 & 13,827 & $<0,001$ \\
FirPerYenilik5 & $<---$ & Yenilik & 0,881 & 0,97 & 0,08 & 12,15 & $<0,001$ \\
FirPerYenilik6 & $<---$ & Yenilik & 0,678 & 0,964 & 0,105 & 9,177 & $<0,001$ \\
\hline
\end{tabular}

$\boldsymbol{\beta}_{\mathbf{0}}:$ Standart Yol Katsayıları, $\boldsymbol{\beta}_{\mathbf{1}}$ : Standart Olmayan Yol Katsayıları

Klan kültürü, çeviklik ve firma performansı değişkenlerinin dâhil edildiği YEM analizi yapılarak, uyum iyiliği indeksleri incelenmiştir. Analizin önerdiği şekilde e4-e5, e19-e20, e20-e21 ve e19e26 değişkenleri arasında kovaryanslar kurulmuştur. Bunun sonucunda elde edilen çözüm ile $\mathrm{CMIN}=676,161, \mathrm{DF}=310, \mathrm{p}<0,001, \mathrm{CMIN} / \mathrm{DF}=2,181, \mathrm{RMSEA}=0,092, \mathrm{NFI}=0,785, \mathrm{CFI}=0,869$, $\mathrm{GFI}=0,759$ olarak, kabul edilebilir sınırlar içerisinde bulunmuştur. Bu da modelin uyumlu olduğu anlamına gelmektedir. Ölçüm modeline ait standart yol katsayıları Şekil 5'de gösterilmektedir. 


\section{Şekil 5: Klan Kültürü Bazında Ölçüm Modeli Standart Yol Katsayıları}

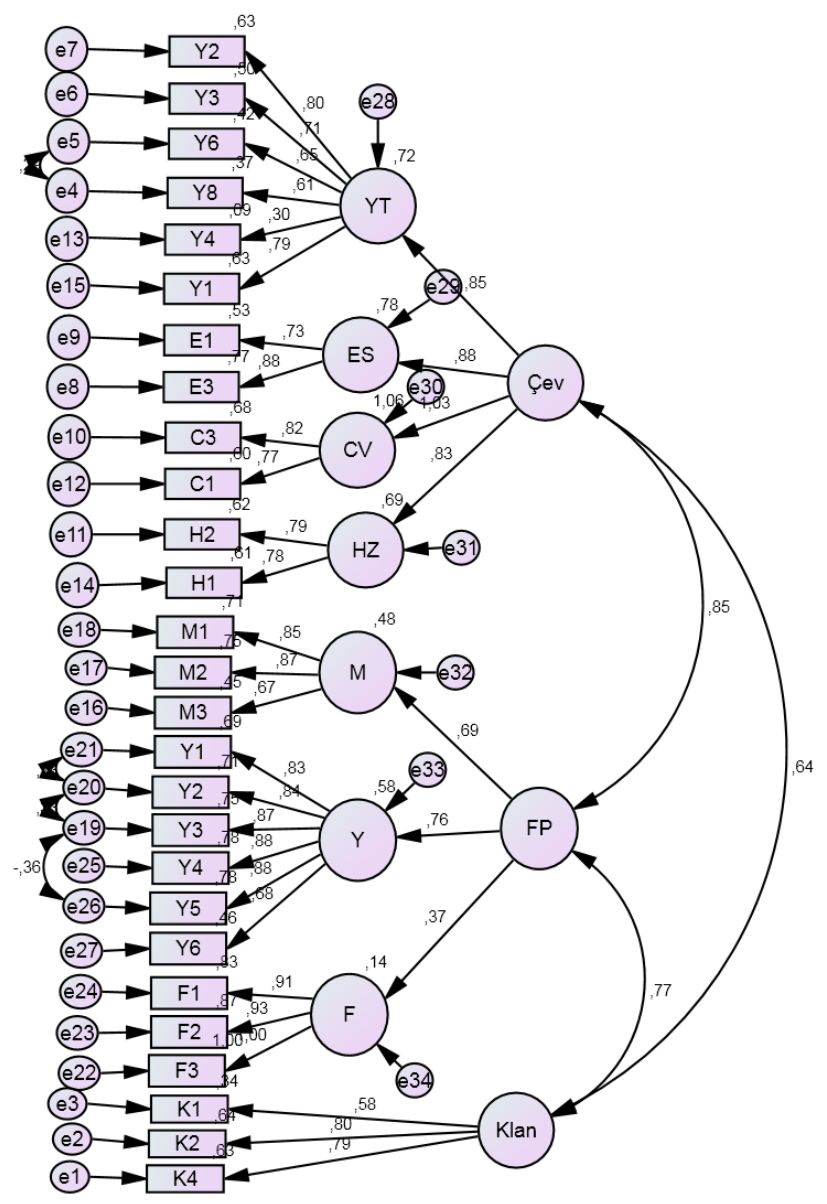

$C M I N=676,161 ; D F=310 ; p=, 000 ; C M I N / D F=2,181 ; G F|=, 759 ; N F|=, 785 ; C F \mid=, 869 ; R M S E A=092$

Ölçüm modeli kapsamında, analiz sonuçlarındaki tahminler incelendiğinde Adhokrasi kültürü, çeviklik ve firma performansı değişkenlerine ait elde edilen tüm katsayıların istatistiksel olarak anlamlı olduğu gözlemlenmiştir. Buna ait veriler Tablo 6'de listelenmiştir.

Tablo 6: Ölçüm Modeline Ait Yol Katsayıları ve Anlamlılık Düzeyleri (Adhokrasi Kültürü)

\begin{tabular}{lllccccc}
\hline Ölçüm Modeli & & & $\boldsymbol{\beta}_{\mathbf{0}}$ & $\boldsymbol{\beta}_{\mathbf{1}}$ & S.E. & C.R. & P \\
\hline Yetkinlik & $<---$ & Ceviklik & 0,928 & 1,061 & 0,163 & 6,502 & $<0,001$ \\
Esneklik & $<---$ & Ceviklik & 0,874 & 1,286 & 0,162 & 7,929 & $<0,001$ \\
CevapVerme & $<---$ & Ceviklik & 0,972 & 1,283 & 0,155 & 8,271 & $<0,001$ \\
HIZ & $<---$ & Ceviklik & 0,825 & 1 & & & \\
MusteriTutma & $<---$ & FirPerf & 0,719 & 1,217 & 0,304 & 4,002 & $<0,001$ \\
Yenilik & $<---$ & FirPerf & 0,684 & 1,757 & 0,414 & 4,249 & $<0,001$
\end{tabular}




\begin{tabular}{|c|c|c|c|c|c|c|c|}
\hline Finansal & $<---$ & FirPerf & 0,412 & 1 & & & \\
\hline AgileYetkin8 & $<---$ & Yetkinlik & 0,648 & 1 & & & \\
\hline AgileYetkin6 & $<---$ & Yetkinlik & 0,694 & 0,954 & 0,121 & 7,866 & $<0,001$ \\
\hline AgileYetkin3 & $<---$ & Yetkinlik & 0,718 & 0,83 & 0,117 & 7,089 & $<0,001$ \\
\hline AgileYetkin2 & $<---$ & Yetkinlik & 0,711 & 0,88 & 0,126 & 7,006 & $<0,001$ \\
\hline AgileEsnek3 & $<---$ & Esneklik & 0,878 & 1 & & & \\
\hline AgileEsnek1 & $<---$ & Esneklik & 0,726 & 0,834 & 0,093 & 8,949 & $<0,001$ \\
\hline AgileCevap3 & $<---$ & CevapVerme & 0,834 & 1 & & & \\
\hline AgileHiz2 & $<--$ & HIZ & 0,803 & 1 & & & \\
\hline AgileCevap1 & $<---$ & CevapVerme & 0,765 & 0,923 & 0,091 & 10,088 & $<0,001$ \\
\hline AgileYetkin4 & $<---$ & Yetkinlik & 0,282 & 0,354 & 0,116 & 3,061 & 0,002 \\
\hline AgileHiz1 & $<---$ & HIZ & 0,762 & 0,916 & 0,112 & 8,213 & $<0,001$ \\
\hline AgileYetkin1 & $<---$ & Yetkinlik & 0,723 & 1,023 & 0,144 & 7,102 & $<0,001$ \\
\hline FirPerMusteri3 & $<---$ & MusteriTutma & 0,677 & 1 & & & \\
\hline FirPerMusteri2 & $<---$ & MusteriTutma & 0,868 & 1,299 & 0,154 & 8,458 & $<0,001$ \\
\hline FirPerMusteri1 & $<---$ & MusteriTutma & 0,838 & 1,356 & 0,163 & 8,337 & $<0,001$ \\
\hline FirPerYenilik3 & $<--$ & Yenilik & 0,888 & 1 & & & \\
\hline FirPerYenilik2 & $<---$ & Yenilik & 0,903 & 1,013 & 0,064 & 15,789 & $<0,001$ \\
\hline FirPerYenilik1 & $<---$ & Yenilik & 0,859 & 0,994 & 0,07 & 14,215 & $<0,001$ \\
\hline FinansalPer3 & $<---$ & Finansal & 0,997 & 1 & & & \\
\hline FinansalPer2 & $<---$ & Finansal & 0,932 & 0,936 & 0,034 & 27,235 & $<0,001$ \\
\hline FinansalPer1 & $<---$ & Finansal & 0,913 & 0,938 & 0,039 & 24,28 & $<0,001$ \\
\hline FirPerYenilik4 & $<---$ & Yenilik & 0,844 & 0,877 & 0,064 & 13,682 & $<0,001$ \\
\hline FirPerYenilik5 & $<---$ & Yenilik & 0,81 & 0,871 & 0,069 & 12,617 & $<0,001$ \\
\hline FirPerYenilik6 & $<---$ & Yenilik & 0,668 & 0,928 & 0,1 & 9,249 & $<0,001$ \\
\hline Adhokrasi4 & $<---$ & Adh & 0,919 & 1 & & & \\
\hline Adhokrasi2 & $<---$ & Adh & 0,825 & 0,973 & 0,078 & 12,54 & $<0,001$ \\
\hline Adhokrasi1 & $<--$ & Adh & 0,377 & 0,47 & 0,105 & 4,474 & $<0,001$ \\
\hline
\end{tabular}

$\boldsymbol{\beta}_{0}$ : Standart Yol Katsayıları, $\boldsymbol{\beta}_{1}$ : Standart Olmayan Yol Katsayıları

Adhokrasi kültürü, çeviklik ve firma performansı değişkenlerinin dâhil edildiği YEM analizi yapılarak, uyum iyiliği indeksleri incelenmiştir. Analizin önerdiği şekilde e4-e5, e7-e15, ve e25- 
e26 değişkenleri arasında kovaryanslar kurulmuştur. Bunun sonucunda elde edilen çözüm ile $\mathrm{CMIN}=593,283, \mathrm{DF}=311, \mathrm{p}<0,001, \mathrm{CMIN} / \mathrm{DF}=1,908, \mathrm{RMSEA}=0,081, \mathrm{NFI}=0,812, \mathrm{CFI}=0,900$, $\mathrm{GFI}=0,776$ olarak, kabul edilebilir sınırlar içerisinde bulunmuştur. Bu da modelin uyumlu olduğu anlamına gelmektedir. Ölçüm modeline ait standart yol katsayıları Şekil 6'de gösterilmektedir.

\section{Şekil 6: Adhokrasi Kültürü Bazında Ölçüm Modeli Standart Yol Katsayıları}

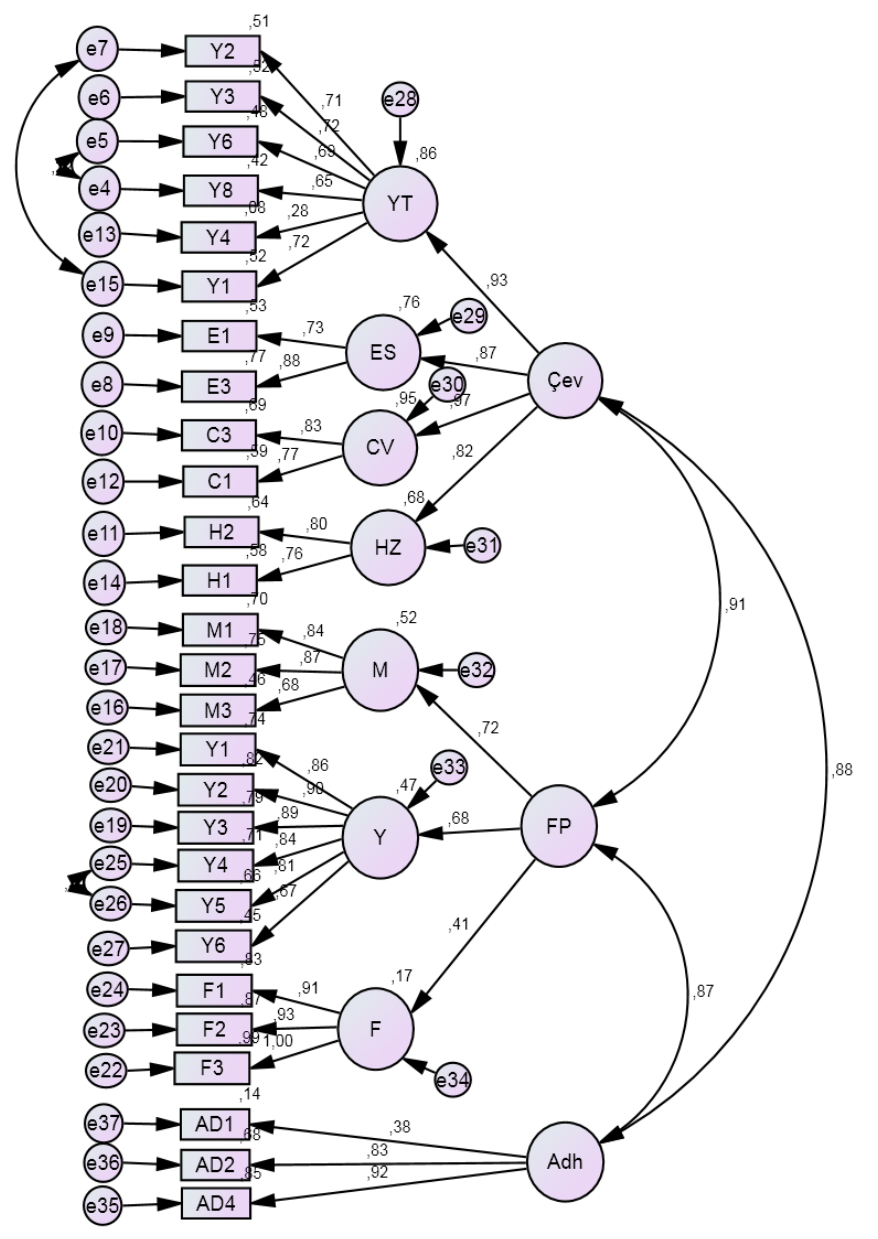

CMIN=593,283; DF=311; $p=, 000 ; C M I N / D F=1,908 ; G F I=, 776 ; N F I=, 812 ; C F I=, 900 ; R M S E A=, 081$

Ölçüm modeli kapsamında, analiz sonuçlarındaki tahminler incelendiğinde Hiyerarşi kültürü, çeviklik ve firma performansı değişkenlerine ait elde edilen tüm katsayıların istatistiksel olarak anlamlı olduğu gözlemlenmiştir. Buna ait veriler Tablo 7’de listelenmiştir.

Tablo 7: Ölçüm Modeline Ait Yol Katsayıları ve Anlamlılık Düzeyleri (Hiyerarşi Kültürü)

\begin{tabular}{lccccccc}
\hline Ölçüm Modeli & & & $\boldsymbol{\beta}_{\mathbf{0}}$ & $\boldsymbol{\beta}_{\mathbf{1}}$ & S.E. & C.R. & P \\
\hline Yetkinlik & $<--$ & Ceviklik & 0,934 & 1,108 & 0,176 & 6,301 & $<0,001$
\end{tabular}




\begin{tabular}{|c|c|c|c|c|c|c|c|}
\hline Esneklik & $<--$ & Ceviklik & 0,851 & 1,322 & 0,176 & 7,497 & $<0,001$ \\
\hline CevapVerme & $<--$ & Ceviklik & 0,992 & 1,337 & 0,17 & 7,844 & $<0,001$ \\
\hline HIZ & $<---$ & Ceviklik & 0,817 & 1 & & & \\
\hline MusteriTutma & $<---$ & FirPerf & 0,707 & 1,047 & 0,243 & 4,315 & $<0,001$ \\
\hline Yenilik & $<---$ & FirPerf & 0,687 & 1,497 & 0,323 & 4,629 & $<0,001$ \\
\hline Finansal & $<---$ & FirPerf & 0,469 & 1 & & & \\
\hline AgileYetkin8 & $<---$ & Yetkinlik & 0,646 & 1 & & & \\
\hline AgileYetkin6 & $<---$ & Yetkinlik & 0,681 & 0,939 & 0,12 & 7,795 & $<0,001$ \\
\hline AgileYetkin3 & $<--$ & Yetkinlik & 0,733 & 0,849 & 0,118 & 7,185 & $<0,001$ \\
\hline AgileYetkin2 & $<---$ & Yetkinlik & 0,705 & 0,875 & 0,126 & 6,951 & $<0,001$ \\
\hline AgileEsnek3 & $<--$ & Esneklik & 0,891 & 1 & & & \\
\hline AgileEsnek1 & $<---$ & Esneklik & 0,715 & 0,809 & 0,094 & 8,626 & $<0,001$ \\
\hline AgileCevap3 & $<--$ & CevapVerme & 0,819 & 1 & & & \\
\hline AgileHiz2 & $<--$ & HIZ & 0,78 & 1 & & & \\
\hline AgileCevap1 & $<---$ & CevapVerme & 0,779 & 0,957 & 0,093 & 10,239 & $<0,001$ \\
\hline AgileYetkin4 & $<--$ & Yetkinlik & 0,328 & 0,413 & 0,117 & 3,536 & $<0,001$ \\
\hline AgileHiz1 & $<---$ & HIZ & 0,785 & 0,972 & 0,12 & 8,127 & $<0,001$ \\
\hline AgileYetkin1 & $<---$ & Yetkinlik & 0,704 & 0,998 & 0,144 & 6,941 & $<0,001$ \\
\hline FirPerMusteri3 & $<---$ & MusteriTutma & 0,673 & 1 & & & \\
\hline FirPerMusteri2 & $<---$ & MusteriTutma & 0,871 & 1,311 & 0,156 & 8,383 & $<0,001$ \\
\hline FirPerMusteri1 & $<---$ & MusteriTutma & 0,838 & 1,365 & 0,165 & 8,268 & $<0,001$ \\
\hline FirPerYenilik3 & $<--$ & Yenilik & 0,856 & 1 & & & \\
\hline FirPerYenilik2 & $<---$ & Yenilik & 0,874 & 1,017 & 0,062 & 16,486 & $<0,001$ \\
\hline FirPerYenilik1 & $<---$ & Yenilik & 0,864 & 1,037 & 0,08 & 12,982 & $<0,001$ \\
\hline FinansalPer3 & $<--$ & Finansal & 0,997 & 1 & & & \\
\hline FinansalPer2 & $<---$ & Finansal & 0,932 & 0,936 & 0,034 & 27,28 & $<0,001$ \\
\hline FinansalPer1 & $<---$ & Finansal & 0,913 & 0,939 & 0,039 & 24,309 & $<0,001$ \\
\hline FirPerYenilik4 & $<--$ & Yenilik & 0,854 & 0,921 & 0,073 & 12,616 & $<0,001$ \\
\hline FirPerYenilik5 & $<---$ & Yenilik & 0,832 & 0,928 & 0,077 & 12,066 & $<0,001$ \\
\hline FirPerYenilik6 & $<--$ & Yenilik & 0,681 & 0,981 & 0,108 & 9,063 & $<0,001$ \\
\hline Hiyerarsi4 & $<---$ & Hiyerarsi & 0,716 & 1 & & & \\
\hline
\end{tabular}




$\begin{array}{llllllll}\text { Hiyerarsi3 } & <--- & \text { Hiyerarsi } & 0,621 & 0,977 & 0,163 & 5,988 & <0,001 \\ \text { Hiyerarsi2 } & <--- & \text { Hiyerarsi } & 0,456 & 0,674 & 0,148 & 4,566 & <0,001 \\ \text { Hiyerarsi1 } & <--- & \text { Hiyerarsi } & 0,348 & 0,565 & 0,16 & 3,524 & <0,001\end{array}$

$\boldsymbol{\beta}_{0}$ : Standart Yol Katsayıları, $\boldsymbol{\beta}_{\mathbf{1}}$ : Standart Olmayan Yol Katsayıları

Hiyerarşi kültürü, çeviklik ve firma performansı değişkenlerinin dâhil edildiği YEM analizi yapılarak, uyum iyiliği indeksleri incelenmiştir. Analizin önerdiği şekilde e4-e5, e7-e15, e19-e20, e25-e26 ve e37-e38 değişkenleri arasında kovaryanslar kurulmuştur. Bunun sonucunda elde edilen çözüm ile CMIN=671,080, DF=335, p<0,001, CMIN/DF=2,003, RMSEA=0,085, NFI=0,786, $\mathrm{CFI}=0,878$, GFI=0,765 olarak, kabul edilebilir sınırlar içerisinde bulunmuştur. $\mathrm{Bu}$ da modelin uyumlu olduğu anlamına gelmektedir. Ölçüm modeline ait standart yol katsayıları Şekil 7'de gösterilmektedir.

\section{Şekil 7: Hiyerarşi Kültürü Bazında Ölçüm Modeli Standart Yol Katsayıları}

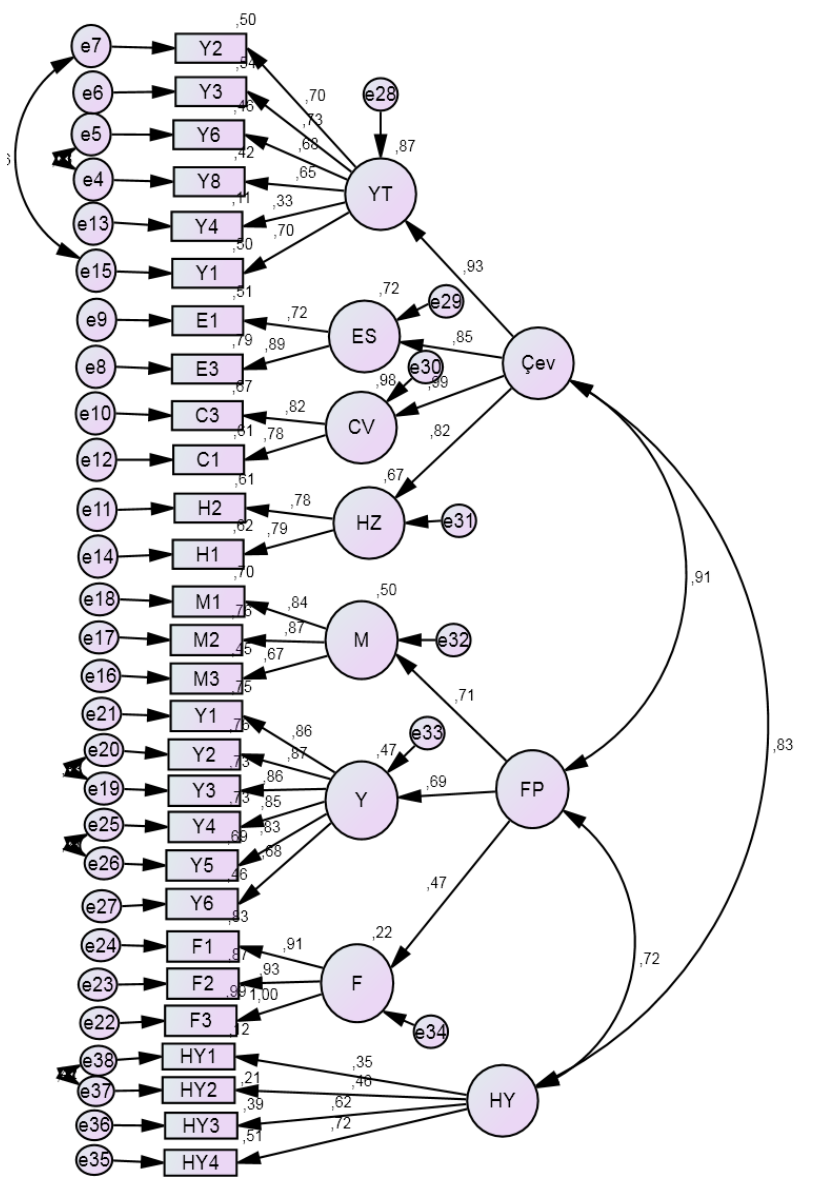

$\mathrm{CMIN}=671,080 ; \mathrm{DF}=335 ; \mathrm{p}=, 000 ; \mathrm{CMIN} / \mathrm{DF}=2,003 ; \mathrm{GFI}=, 765 ; \mathrm{NFI}=, 786 ; \mathrm{CFI}=, 878 ; \mathrm{RMSEA}=, 085$ 
Ölçüm modeli kapsamında, analiz sonuçlarındaki tahminler incelendiğinde Pazar kültürü, çeviklik ve firma performansı değişkenlerine ait elde edilen tüm katsayıların istatistiksel olarak anlamlı olduğu gözlemlenmiştir. Buna ait veriler Tablo 8'da listelenmiştir.

Tablo 8: Ölçüm Modeline Ait Yol Katsayıları ve Anlamlılık Düzeyleri (Pazar Kültürü)

\begin{tabular}{|c|c|c|c|c|c|c|c|}
\hline Ölçüm Modeli & & & $\boldsymbol{\beta}_{0}$ & $\beta_{1}$ & S.E. & C.R. & $\mathbf{P}$ \\
\hline Yetkinlik & $\begin{array}{l}<-- \\
\end{array}$ & Ceviklik & 0,960 & 1,101 & 0,18 & 6,122 & $<0,001$ \\
\hline Esneklik & $<---$ & Ceviklik & 0,812 & 1,289 & 0,179 & 7,204 & $<0,001$ \\
\hline CevapVerme & $<---$ & Ceviklik & 0,968 & 1,355 & 0,174 & 7,77 & $<0,001$ \\
\hline HIZ & $<---$ & Ceviklik & 0,818 & 1 & & & \\
\hline MusteriTutma & $<---$ & FirPerf & 0,696 & 1,011 & 0,231 & 4,385 & $<0,001$ \\
\hline Yenilik & $<---$ & FirPerf & 0,688 & 1,452 & 0,305 & 4,759 & $<0,001$ \\
\hline Finansal & $<---$ & FirPerf & 0,477 & 1 & & & \\
\hline AgileYetkin8 & $<---$ & Yetkinlik & 0,617 & 1 & & & \\
\hline AgileYetkin6 & $<---$ & Yetkinlik & 0,669 & 0,966 & 0,127 & 7,625 & $<0,001$ \\
\hline AgileYetkin3 & $<---$ & Yetkinlik & 0,719 & 0,871 & 0,127 & 6,856 & $<0,001$ \\
\hline AgileYetkin2 & $<---$ & Yetkinlik & 0,723 & 0,939 & 0,137 & 6,865 & $<0,001$ \\
\hline AgileEsnek3 & $<---$ & Esneklik & 0,900 & 1 & & & \\
\hline AgileEsnek1 & $<--$ & Esneklik & 0,708 & 0,794 & 0,097 & 8,202 & $<0,001$ \\
\hline AgileCevap3 & $<---$ & CevapVerme & 0,840 & 1 & & & \\
\hline AgileHiz2 & $<---$ & HIZ & 0,769 & 1 & & & \\
\hline AgileCevap1 & $<--$ & CevapVerme & 0,759 & 0,909 & 0,091 & 9,993 & $<0,001$ \\
\hline AgileYetkin4 & $<--$ & Yetkinlik & 0,330 & 0,434 & 0,123 & 3,541 & $<0,001$ \\
\hline AgileHiz1 & $<---$ & HIZ & 0,796 & 0,998 & 0,123 & 8,141 & $<0,001$ \\
\hline AgileYetkin 1 & $<---$ & Yetkinlik & 0,736 & 1,092 & 0,157 & 6,952 & $<0,001$ \\
\hline FirPerMusteri3 & $<---$ & MusteriTutma & 0,671 & 1 & & & \\
\hline FirPerMusteri2 & $<---$ & MusteriTutma & 0,875 & 1,321 & 0,158 & 8,367 & $<0,001$ \\
\hline FirPerMusteri1 & $<---$ & MusteriTutma & 0,836 & 1,365 & 0,166 & 8,234 & $<0,001$ \\
\hline FirPerYenilik3 & $<---$ & Yenilik & 0,843 & 1 & & & $<0,001$ \\
\hline FirPerYenilik2 & $<---$ & Yenilik & 0,855 & 1,01 & 0,061 & 16,668 & $<0,001$ \\
\hline
\end{tabular}




\begin{tabular}{lclrrrrr} 
FirPerYenilik1 & $<---$ & Yenilik & 0,877 & 1,069 & 0,082 & 12,967 & $<0,001$ \\
FinansalPer3 & $<---$ & Finansal & 0,997 & 1 & & & \\
FinansalPer2 & $<---$ & Finansal & 0,932 & 0,936 & 0,034 & 27,286 & $<0,001$ \\
FinansalPer1 & $<---$ & Finansal & 0,913 & 0,939 & 0,039 & 24,313 & $<0,001$ \\
FirPerYenilik4 & $<---$ & Yenilik & 0,904 & 0,989 & 0,072 & 13,713 & $<0,001$ \\
FirPerYenilik5 & $<---$ & Yenilik & 0,846 & 0,958 & 0,075 & 12,74 & $<0,001$ \\
FirPerYenilik6 & $<---$ & Yenilik & 0,671 & 0,982 & 0,109 & 8,999 & $<0,001$ \\
Pazar4 & $<---$ & Pazar & 0,737 & 1 & & & \\
Pazar2 & $<---$ & Pazar & 0,186 & 0,215 & 0,109 & 1,974 & 0,048 \\
\hline
\end{tabular}

$\boldsymbol{\beta}_{0}$ : Standart Yol Katsayıları, $\boldsymbol{\beta}_{1}$ : Standart Olmayan Yol Katsayıları

Pazar kültürü, çeviklik ve firma performansı değişkenlerinin dâhil edildiği YEM analizi yapılarak, uyum iyiliği indeksleri incelenmiştir. Analizin önerdiği şekilde e4-e5, e7-e15, e19-e20 ve e21-e25 değişkenleri arasında kovaryanslar kurulmuştur. Bunun sonucunda elde edilen çözüm ile $\mathrm{CMIN}=609,037, \mathrm{DF}=285, \mathrm{p}<0,001, \mathrm{CMIN} / \mathrm{DF}=2,137, \mathrm{RMSEA}=0,090, \mathrm{NFI}=0,796, \mathrm{CFI}=0,879$, $\mathrm{GFI}=0,764$ olarak, kabul edilebilir sınırlar içerisinde bulunmuştur. $\mathrm{Bu}$ da modelin uyumlu olduğu anlamına gelmektedir. Ölçüm modeline ait standart yol katsayıları Şekil 8'de gösterilmektedir. 
Şekil 8: Pazar Kültürü Bazında Ölçüm Modeli Standart Yol Katsayıları

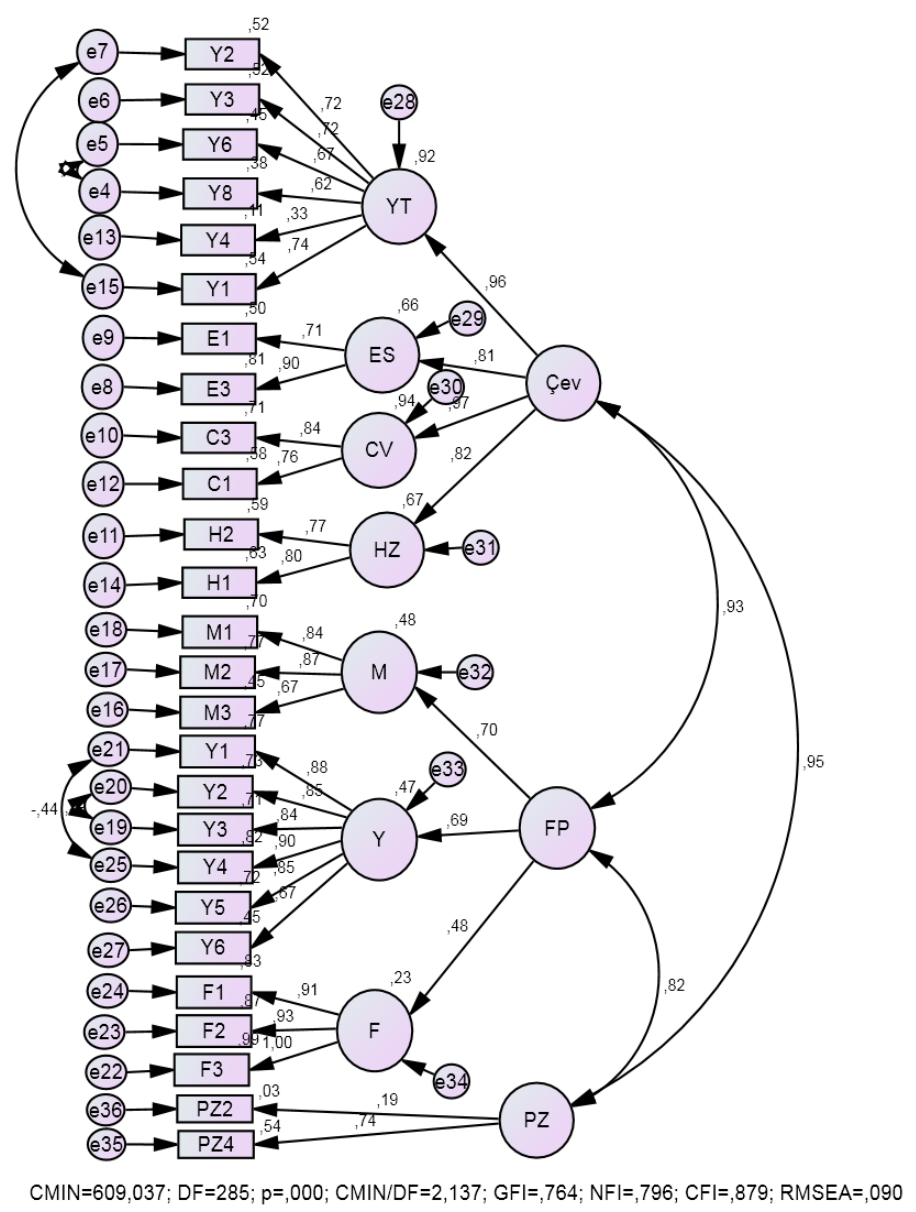

\section{Hipotez Testleri}

Klan kültürü ile firma performansı arasındaki dolaylı etki 0,125 ve \%95 güven aralığ 0,029-0,348 olarak elde edilmiş ve bu aralık 0 değerini içermediği için dolaylı etki istatistiksel olarak anlamlı bulunmuştur. Yapılan analiz sonrasında örgütsel çevikliğin, klan kültürü ve firma performansı arasında kısmi aracılık rolü üstlendiği görülmektedir. Analize ait sonuçlar Tablo 9'de yer almaktadir. 
Tablo 9: Klan Kültürünün Firma Performansı Üzerindeki Etkisinde Örgütsel Çevikliğin Aracılık Rolü

\begin{tabular}{|c|c|c|c|c|}
\hline & \multicolumn{4}{|c|}{ Sonuç Değişkenleri } \\
\hline & \multicolumn{2}{|l|}{$\begin{array}{l}\text { Örgütsel } \\
\text { Çeviklik }\end{array}$} & \multicolumn{2}{|c|}{ Firma Performans1 } \\
\hline & $\beta$ & $\mathrm{SH}$ & $\beta$ & SH \\
\hline Klan Kültürü (a) & $0,382 * *$ & 0,070 & & \\
\hline $\mathrm{R}^{2}$ & \multicolumn{2}{|c|}{0,405} & & \\
\hline Klan Kültürü (c') & & & $0,125^{*}$ & 0,048 \\
\hline Örgütsel Çeviklik (b) & & & $0,326 * *$ & 0,099 \\
\hline $\mathrm{R}^{2}$ & & & & 20 \\
\hline Dolaylı Etki & & & $0,125^{*}$ & $(0,029-0,348)$ \\
\hline
\end{tabular}

$\mathrm{H}_{1}$ hipotezi için oluşturulan modele ait yol katsayıları Şekil 9'da yer almaktadır.

Şekil 9: H1 Hipotez Modeli Yol Katsayıları (Klan Kültürü)

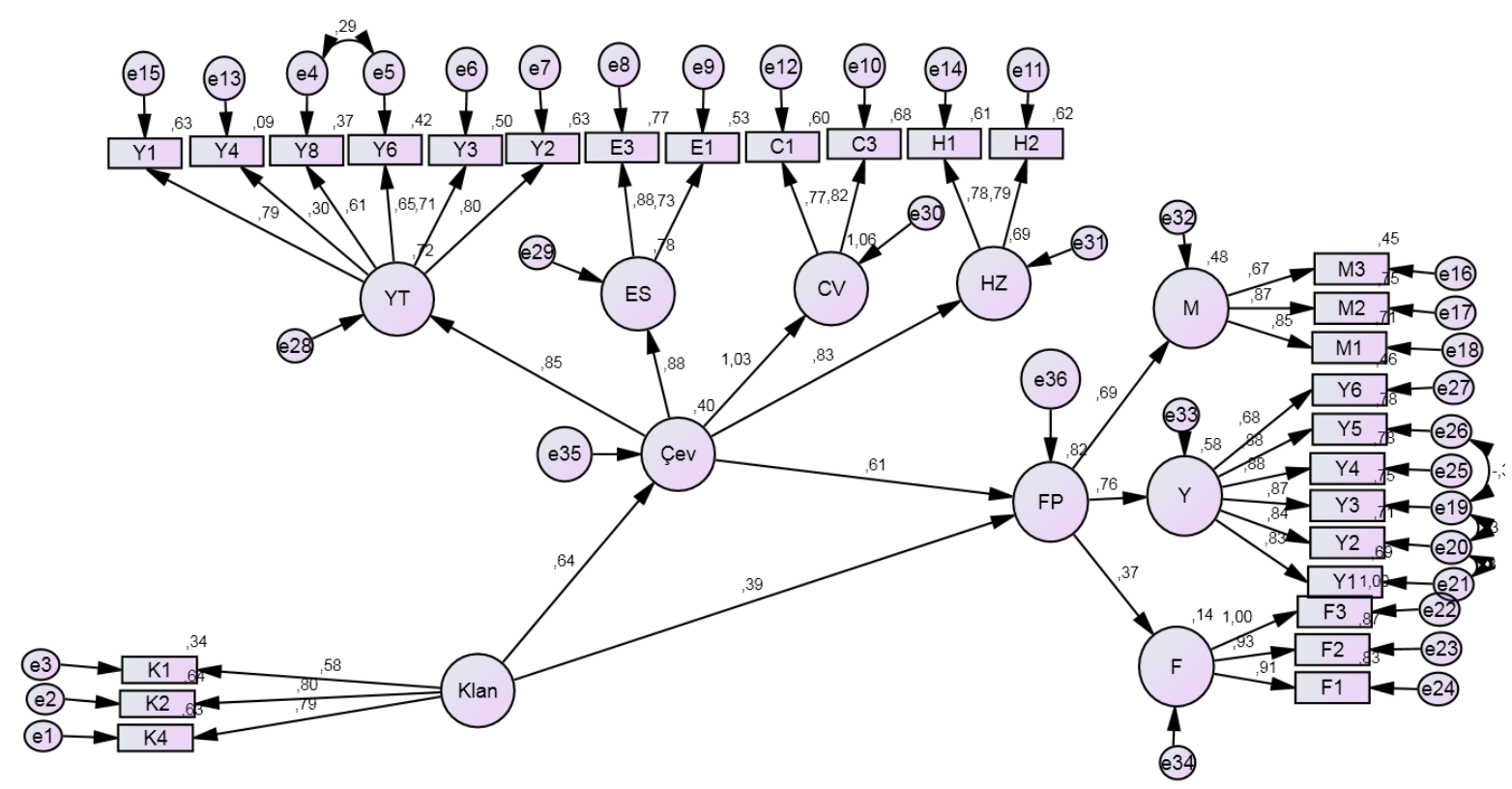

Analiz sonrasında $\mathbf{H}_{1 \mathbf{a}}, \mathbf{H}_{\mathbf{1 b}}$ ve $\mathbf{H}_{1 \mathbf{c}}$ hipotezleri doğrulanmıştır.

Adhokrasi kültürü ile firma performansı arasındaki dolaylı etki 0,213 ve \%95 güven aralığı 0,017-0,764 olarak elde edilmiş ve bu aralık 0 değerini içermediği için dolaylı etki istatistiksel 
olarak anlamlı bulunmuştur. Yapılan analiz sonrasında örgütsel çevikliğin, adhokrasi kültürü ve firma performansı arasında tam aracılık rolü üstlendiği görülmektedir. Analize ait sonuçlar Tablo 10 'da yer almaktadir.

Tablo 10: Adhokrasi Kültürünün Firma Performansı Üzerindeki Etkisinde Örgütsel Çevikliğin Aracılık Rolü

\begin{tabular}{lcccc}
\hline & \multicolumn{4}{c}{ Sonuç Değişkenleri } \\
\cline { 2 - 5 } & \multicolumn{2}{c}{$\begin{array}{l}\text { Örgütsel } \\
\text { Çeviklik }\end{array}$} & \multicolumn{2}{c}{ Firma Performans1 } \\
\cline { 2 - 5 } & $\beta$ & SH & $\beta$ & SH \\
\hline Adhokrasi Kültürü (a) & $0,565^{* *}$ & 0,071 & & \\
$\mathrm{R}^{2}$ & 0,078 & & 0,110 & 0,089 \\
\hline Adhokrasi Kültürü (c') & & & $0,377^{*}$ & 0,158 \\
Örgütsel Çeviklik (b) & & & & 0,847 \\
$\mathrm{R}^{2}$ & & & $0,213^{*}$ & $(0,017-0,764)$ \\
Dolaylı Etki & & & &
\end{tabular}

$\mathrm{H}_{2}$ hipotezi için oluşturulan modele ait yol katsayıları Şekil 10'da yer almaktadır.

Şekil 10: H2 Hipotez Modeli Yol Katsayıları (Adhokrasi Kültürü)

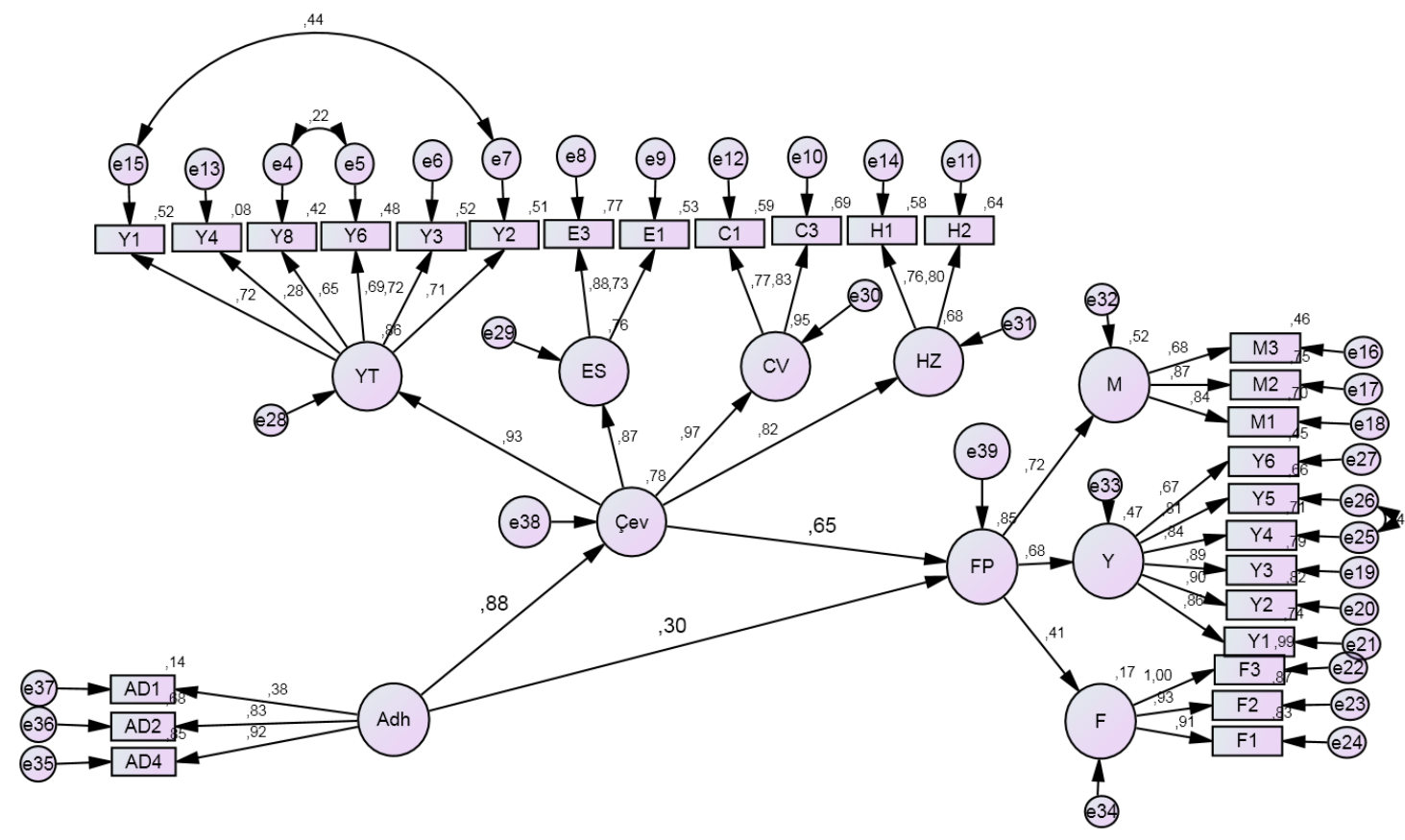


Analiz sonrasında $\mathbf{H}_{2 \mathbf{a}}$ ve $\mathbf{H}_{2 \mathrm{~b}}$ hipotezleri doğrulanmış, fakat $\mathbf{H}_{\mathbf{2 c}}$ hipotezi Adhokrasi kültürünün firma performansındaki doğrudan etkisi anlamsız olduğu için $(\beta=0,110, \quad p=0,218)$ doğrulanmamıştır.

Hiyerarşi kültürü ile firma performansı arasındaki dolaylı etki 0,450 ve $\% 95$ güven aralığı 0,043-1,747 olarak elde edilmiş ve bu aralık 0 değerini içermediği için dolaylı etki istatistiksel olarak anlamlı bulunmuştur. Yapılan analiz sonrasında örgütsel çevikliğin, hiyerarşi kültürü ve firma performansı arasında tam aracılık rolü üstlendiği görülmektedir. Analize ait sonuçlar Tablo 11 'de yer almaktadır.

Tablo 11: Hiyerarşi Kültürünün Firma Performansı Üzerindeki Etkisinde Örgütsel Çevikliğin Aracılık Rolü

\begin{tabular}{|c|c|c|c|c|}
\hline & \multicolumn{4}{|c|}{ Sonuç Değişkenleri } \\
\hline & \multicolumn{4}{|l|}{ Örgütsel } \\
\hline & \multicolumn{2}{|l|}{ Çeviklik } & \multicolumn{2}{|c|}{ Firma Performans1 } \\
\hline & $\beta$ & $\mathrm{SH}$ & $\beta$ & SH \\
\hline Hiyerarşi Kültürü (a) & $0,664 * *$ & 0,123 & & \\
\hline $\mathrm{R}^{2}$ & \multicolumn{2}{|c|}{0,684} & & \\
\hline Hiyerarşi Kültürü (c') & & & $-0,052$ & 0,133 \\
\hline Örgütsel Çeviklik (b) & & & $0,677^{*}$ & 0,203 \\
\hline $\mathrm{R}^{2}$ & & & \multicolumn{2}{|c|}{0,829} \\
\hline Dolaylı Etki & & & $0,450 *$ & $(0,043-1,747)$ \\
\hline
\end{tabular}

$\mathrm{H}_{3}$ hipotezi için oluşturulan modele ait yol katsayıları Şekil 11'da yer almaktadır. 


\section{Şekil 11: H3 Hipotez Modeli Yol Katsayıları (Hiyerarşi Kültürü)}

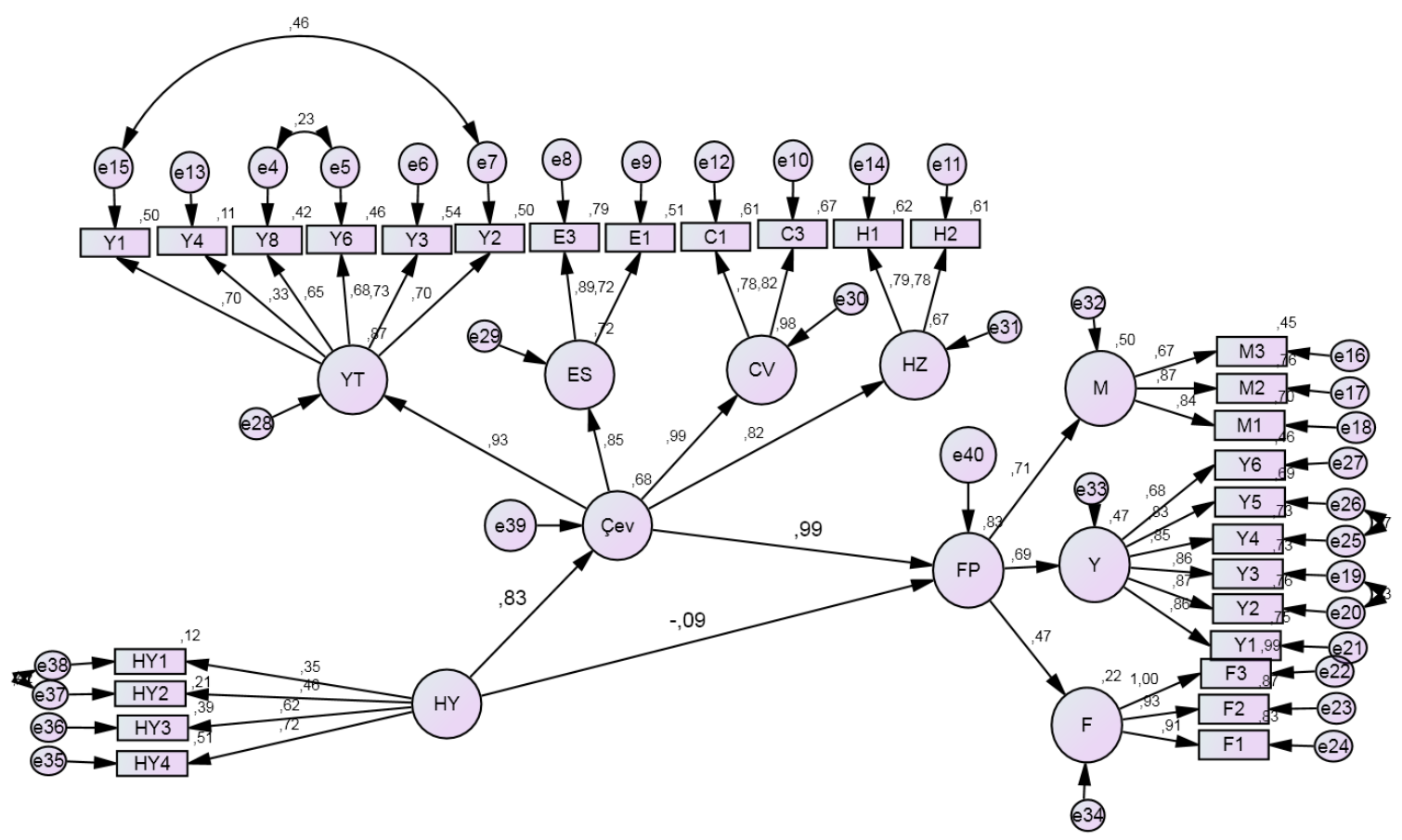

Analiz sonrasında $\mathbf{H}_{3 \mathbf{a}}$ ve $\mathbf{H}_{\mathbf{3 b}}$ hipotezleri doğrulanmış, fakat $\mathbf{H}_{\mathbf{3}}$ hipotezi Hiyerarşi kültürünün firma performansındaki doğrudan etkisi anlamsız olduğu için $(\beta=-0,052, \quad p=0,698)$ doğrulanmamıştır.

Pazar kültürü ile firma performansı arasındaki dolaylı etki 0,888 ve \%95 güven aralığı -0,034-3,005 olarak elde edilmiş ve bu aralık 0 değerini içerdiği için dolaylı etki istatistiksel olarak anlamlı bulunmamıştır. Yapılan analiz sonrasında örgütsel çevikliğin, pazar kültürü ve firma performansı arasında aracılık rolü üstlenmediği görülmektedir. Analize ait sonuçlar Tablo 12'de yer almaktadir.

\section{Tablo12: Pazar Kültürünün Firma Performansı Üzerindeki Etkisinde Örgütsel Çevikliğin} Aracılık Rolü

\begin{tabular}{|c|c|c|c|c|}
\hline & \multicolumn{4}{|c|}{ Sonuç Değişkenleri } \\
\hline & \multicolumn{4}{|l|}{ Örgütsel } \\
\hline & \multicolumn{2}{|l|}{ Çeviklik } & \multicolumn{2}{|c|}{ Firma Performans1 } \\
\hline & $\beta$ & $\mathrm{SH}$ & $\beta$ & SH \\
\hline Pazar Kültürü (a) & $0,793^{*}$ & 0,386 & & \\
\hline $\mathrm{R}^{2}$ & \multicolumn{2}{|c|}{0,905} & & \\
\hline
\end{tabular}


Pazar Kültürü (c')

Örgütsel Çeviklik (b)

$\mathrm{R}^{2}$

Dolayl1 Etki
$-0,406$

1,121

0,911

$* * \mathrm{p}<0,001, * \mathrm{p}<0,05$

$\mathrm{H}_{4}$ hipotezi için oluşturulan modele ait yol katsayıları Şekil 12'da yer almaktadır.

\section{Şekil 12: $\mathrm{H}_{4}$ Hipotez Modeli Yol Katsayıları (Pazar Kültürü)}

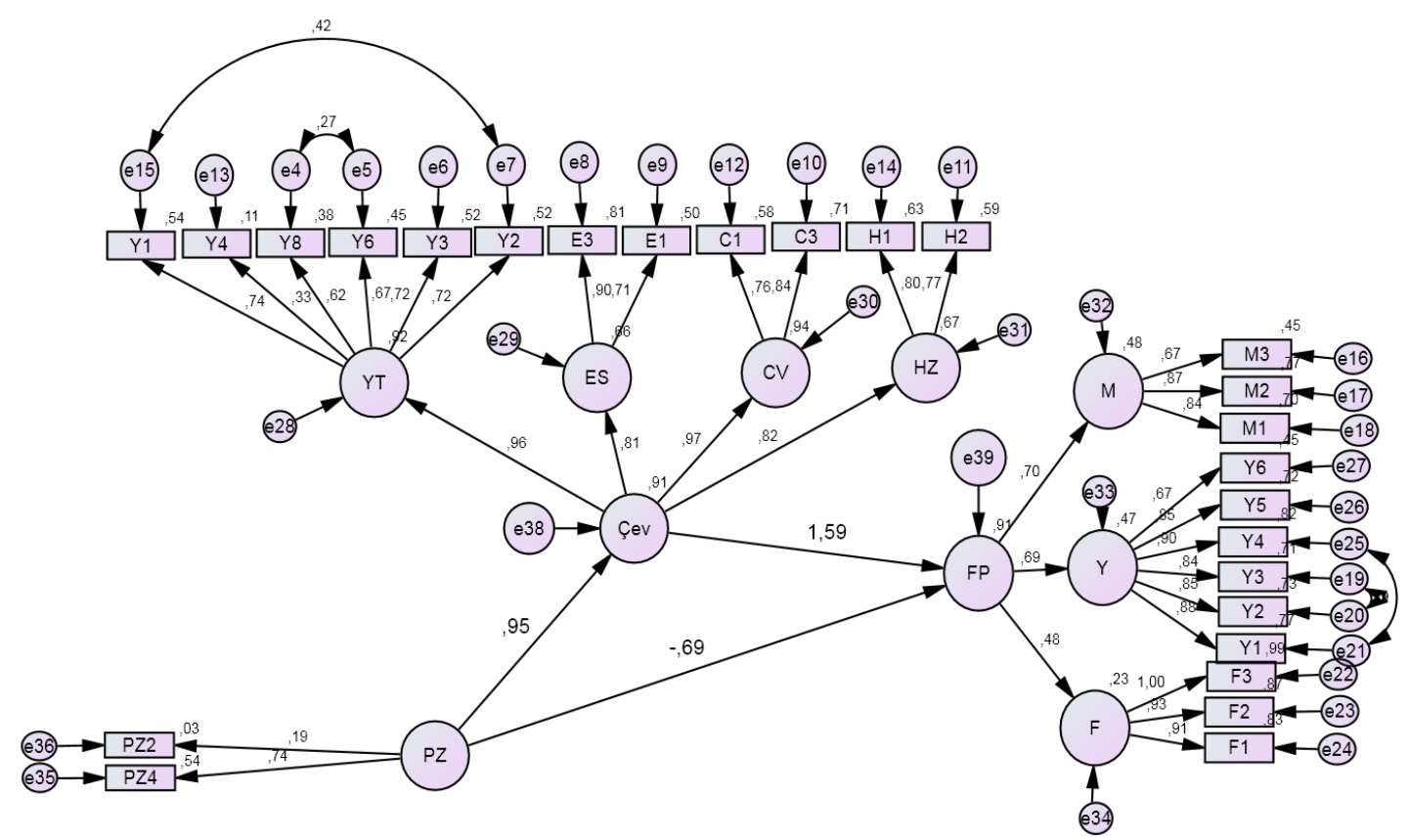

Analiz sonrasında $\mathbf{H}_{4 a}$ hipotezi doğrulanmış, $\mathrm{H}_{4 \mathbf{b}}$ hipotezi ise örgütsel çevikliğin firma performansına etkisi anlamsız olduğu $(\beta=1,121, p=0,638)$ için doğrulanmamıştır. $\mathbf{H}_{4 \mathbf{c}}$ hipotezi de Pazar kültürünün firma performansındaki doğrudan etkisi anlamsız olduğu için $(\beta=-0,406$, $\mathrm{p}=0,845$ ) doğrulanmamıştır.

\subsection{Demografik Özellikler Açısından Fark Testleri}

Hipotezlere ek olarak araştırma kapsamında belirlenen sorulara ait fark testlerinin sonuçları aşağıda yer almaktadır. 


\section{Örgüt kültürü algılarının demografik özellikler açısından farklılıkları}

Cinsiyet, medeni durum, çalışma şekli, eğitim düzeyi açısından örgüt kültürü algılarında anlamlı farklılık tespit edilememiştir. Bununla birlikte, grupları arasında anlamlı farklılıklar tespit edilen değişkenlere ait sonuçlar Tablo 13 ve Tablo 14'de listelenmiştir. Bu sonuçlara göre klan ve hiyerarşi kültürlerinde yönetici olanlar ile olmayanlar arasında, Pazar kültüründe sektörlere göre, tüm örgüt türlerinde firma faaliyet yaşına göre $p<0,05$ bulunmuştur.

Tablo14: Örgüt Kültürünün t-Testi Sonuçları

\begin{tabular}{|c|c|c|c|c|c|c|c|}
\hline Örgüit Kültürü & & Grup & $\mathbf{N}$ & Ort. & SS & $\mathbf{t}$ & $\mathbf{p}$ \\
\hline \multirow{2}{*}{ Klan } & Yönetici & Evet & 85 & 3,59 & 0,93 & \multirow{2}{*}{2,086} & \multirow{2}{*}{0,039} \\
\hline & mi? & Hayır & 55 & 3,24 & 1,00 & & \\
\hline \multirow{2}{*}{ Hiyerarşi } & Yönetici & Evet & 85 & 3,65 & 0,83 & - & \multirow{2}{*}{0,033} \\
\hline & mi? & Hayır & 55 & 3,96 & 0,83 & 2,150 & \\
\hline
\end{tabular}

Tablo14: Örgüt Kültürünün ANOVA-Testi Sonuçları

\begin{tabular}{|c|c|c|c|c|c|c|c|}
\hline Örgüt Külttürü & & Grup & $\mathbf{N}$ & Ort. & SS & $\mathbf{F}$ & $\mathbf{p}$ \\
\hline \multirow{5}{*}{ Pazar } & \multirow{5}{*}{ Sektör } & Hizmet & 41 & 4,28 & 0,56 & \multirow{5}{*}{3,097} & \multirow{5}{*}{0,018} \\
\hline & & IT & 12 & 3,58 & 0,76 & & \\
\hline & & İmalat & 79 & 4,05 & 0,71 & & \\
\hline & & Perakende & 7 & 3,79 & 0,70 & & \\
\hline & & Tarım & 1 & 3,50 & & & \\
\hline \multirow{7}{*}{ Klan } & \multirow{7}{*}{$\begin{array}{c}\text { Firma } \\
\text { Faaliyet } \\
\text { Yaşı }\end{array}$} & $0-5$ Yil & 8 & 4,50 & 0,64 & \multirow{7}{*}{2,770} & \multirow{7}{*}{0,014} \\
\hline & & 6-10 Y11 & 24 & 3,47 & 1,16 & & \\
\hline & & 11-20 Y1l & 31 & 3,19 & 1,15 & & \\
\hline & & 21-30 Y11 & 20 & 3,72 & 0,71 & & \\
\hline & & $31-50 \mathrm{Y}_{11}$ & 13 & 3,43 & 0,86 & & \\
\hline & & 51-90 Y11 & 22 & 3,14 & 0,73 & & \\
\hline & & 91 Y1l ve Üzeri & 22 & 3,50 & 0,78 & & \\
\hline \multirow{2}{*}{ Adhokrasi } & & $0-5$ Y1l & 8 & 4,54 & 0,50 & \multirow{2}{*}{3,600} & \multirow{2}{*}{0,002} \\
\hline & & 6-10 Y11 & 24 & 3,81 & 1,05 & & \\
\hline
\end{tabular}




\begin{tabular}{|c|c|c|c|c|c|}
\hline & \multirow{5}{*}{$\begin{array}{c}\text { Firma } \\
\text { Faaliyet } \\
\text { Yaşı }\end{array}$} & $11-20 Y_{11}$ & \\
\hline & & 21-30 Y1l & 203,68 & 0,92 & \\
\hline & & $31-50 \mathrm{Y}_{11}$ & $13 \quad 3,33$ & 0,92 & \\
\hline & & $51-90 Y_{11}$ & $22 \quad 3,05$ & 0,76 & \\
\hline & & 91 Y1l ve Üzeri & & & \\
\hline \multirow{7}{*}{ Hiyerarşi } & \multirow{7}{*}{$\begin{array}{c}\text { Firma } \\
\text { Faaliyet } \\
\text { Yaşı }\end{array}$} & $0-5$ Y1l & $8 \quad 3,97$ & 0,99 & \multirow{7}{*}{$2,965 \quad 0,010$} \\
\hline & & 6-10 Y11 & $24 \quad 4,18$ & 1,05 & \\
\hline & & $11-20 \mathrm{Y}_{11}$ & $31 \quad 3,35$ & 0,70 & \\
\hline & & 21-30 Y11 & $20 \quad 3,89$ & 0,52 & \\
\hline & & $31-50 \mathrm{Y}_{11}$ & $13 \quad 3,44$ & 0,75 & \\
\hline & & $\overline{51-90 \mathrm{Y}_{11}}$ & $22 \quad 3,84$ & 0,51 & \\
\hline & & 91 Y1l ve Üzeri & 223,86 & 1,03 & \\
\hline \multirow{7}{*}{ Pazar } & \multirow{7}{*}{$\begin{array}{c}\text { Firma } \\
\text { Faaliyet } \\
\text { Yaşı }\end{array}$} & $0-5$ Y1l & $8 \quad 4,44$ & 0,62 & \multirow{7}{*}{$2,181 \quad 0,049$} \\
\hline & & $\overline{6-10 ~ Y 11}$ & $24 \quad 4,40$ & 0,72 & \\
\hline & & $11-20 Y_{11}$ & $31 \quad 3,87$ & 0,86 & \\
\hline & & $21-30 Y_{11}$ & $20 \quad 3,98$ & 0,68 & \\
\hline & & $31-50 Y_{11}$ & $13 \quad 3,81$ & 0,52 & \\
\hline & & $51-90 Y_{11}$ & 224,05 & 0,41 & \\
\hline & & 91 Yil ve Üzeri & $22 \quad 4,07$ & 0,62 & \\
\hline
\end{tabular}

\section{Örgütsel çeviklik algılarının demografik özellikler açısından farklılıkları}

Cinsiyet, medeni durum, çalışma şekli, eğitim düzeyi açısından örgütsel çeviklik algılarında anlamlı farklılık tespit edilememiştir. Bununla birlikte, grupları arasında anlamlı farklılıklar tespit edilen değişkenlere ait sonuçlar Tablo 15'de listelenmiştir. Bu sonuçlara göre örgütsel çevikliğin esneklik ve hız boyutlarında iş yeri kıdemine göre, yetkinlik, hız ve cevap verme boyutları ve genel çeviklik düzeylerinde firma faaliyet yaşına göre, cevap verme ve hız boyutlarında firma büyüklüğ̈̈ne göre $\mathrm{p}<0,05$ bulunmuştur. 
Tablo15: Örgütsel Çeviklik ANOVA-Testi Sonuçları

\begin{tabular}{|c|c|c|c|c|c|c|c|}
\hline Örgütsel Çeviklik & & Grup & $\mathbf{N}$ & Ort. & SS & $\mathbf{F}$ & $\mathbf{p}$ \\
\hline \multirow{5}{*}{ Esneklik } & \multirow{5}{*}{$\begin{array}{l}\text { İş Yeri } \\
\text { Kıdemi }\end{array}$} & $0-5$ Yil & 55 & 3,40 & 1,12 & \multirow{5}{*}{3,587} & \multirow{5}{*}{0,008} \\
\hline & & 6-10 Y11 & 29 & 3,55 & 0,95 & & \\
\hline & & 11-15 Y11 & 16 & 3,56 & 0,95 & & \\
\hline & & 16-20 Y11 & 16 & 3,48 & 0,70 & & \\
\hline & & 21 Y1l ve Üzeri & 24 & 3,36 & 0,84 & & \\
\hline \multirow{5}{*}{ Hiz } & \multirow{5}{*}{$\begin{array}{l}\text { İş Yeri } \\
\text { Kıdemi }\end{array}$} & $0-5$ Y1l & 55 & 3,40 & 1,12 & \multirow{5}{*}{2,940} & \multirow{5}{*}{0,023} \\
\hline & & 6-10 Y11 & 29 & 3,55 & 0,95 & & \\
\hline & & $11-15 Y_{11}$ & 16 & 3,56 & 0,95 & & \\
\hline & & 16-20 Y11 & 16 & 3,48 & 0,70 & & \\
\hline & & 21 Y1l ve Üzeri & 24 & 3,36 & 0,84 & & \\
\hline \multirow{5}{*}{ Genel Çeviklik } & \multirow{5}{*}{$\begin{array}{l}\text { İş Yeri } \\
\text { Kıdemi }\end{array}$} & $0-5$ Y 11 & 55 & 3,40 & 1,12 & \multirow{5}{*}{2,492} & \multirow{5}{*}{0,046} \\
\hline & & 6-10 Y11 & 29 & 3,55 & 0,95 & & \\
\hline & & 11-15 Y1l & 16 & 3,56 & 0,95 & & \\
\hline & & 16-20 Y1l & 16 & 3,48 & 0,70 & & \\
\hline & & 21 Y1l ve Üzeri & 24 & 3,36 & 0,84 & & \\
\hline \multirow{7}{*}{ Yetkinlik } & \multirow{7}{*}{$\begin{array}{c}\text { Firma } \\
\text { Faaliyet } \\
\text { Yaşı }\end{array}$} & $0-5$ Yil & 8 & 4,44 & 0,57 & \multirow{7}{*}{2,913} & \multirow{7}{*}{0,011} \\
\hline & & 6-10 Y11 & 24 & 4,24 & 0,76 & & \\
\hline & & 11-20 Y1l & 31 & 3,84 & 0,82 & & \\
\hline & & $21-30 Y_{11}$ & 20 & 4,14 & 0,56 & & \\
\hline & & $31-50$ Y11 & 13 & 3,71 & 0,76 & & \\
\hline & & 51-90 Y11 & 22 & 3,87 & 0,44 & & \\
\hline & & 91 Y11 ve Üzeri & 22 & 4,35 & 0,53 & & \\
\hline \multirow{6}{*}{ Esneklik } & \multirow{6}{*}{$\begin{array}{c}\text { Firma } \\
\text { Faaliyet } \\
\text { Yaşı }\end{array}$} & $0-5 Y_{11}$ & 8 & 4,50 & 0,60 & \multirow{6}{*}{4,353} & \multirow{6}{*}{0,000} \\
\hline & & 6-10 Y11 & 24 & 4,15 & 1,05 & & \\
\hline & & 11-20 Y11 & 31 & 3,95 & 0,97 & & \\
\hline & & 21-30 Y1l & 20 & 3,95 & 0,87 & & \\
\hline & & $31-50$ Y1l & 13 & 3,46 & 0,75 & & \\
\hline & & $51-90$ Y1l & 22 & 3,09 & 0,87 & & \\
\hline
\end{tabular}




\begin{tabular}{|c|c|c|c|c|c|c|}
\hline & & 91 Y1l ve Üzeri & 22 & 4,05 & 0,89 & \\
\hline \multirow{7}{*}{ Cevap Verme } & \multirow{7}{*}{$\begin{array}{c}\text { Firma } \\
\text { Faaliyet } \\
\text { Yaşı }\end{array}$} & $0-5 Y_{11}$ & 8 & 4,50 & 0,53 & \multirow{7}{*}{$4,221 \quad 0,001$} \\
\hline & & 6-10 Y1l & 24 & 4,25 & 1,03 & \\
\hline & & $11-20$ Y11 & 31 & 4,00 & 0,82 & \\
\hline & & 21-30 Y11 & 20 & 4,00 & 0,95 & \\
\hline & & 31-50 Yil & 13 & 3,54 & 0,75 & \\
\hline & & 51-90 Y11 & 22 & 3,25 & 0,81 & \\
\hline & & 91 Y11 ve Üzeri & 22 & 4,16 & 0,81 & \\
\hline \multirow{7}{*}{ Genel Çeviklik } & \multirow{7}{*}{$\begin{array}{c}\text { Firma } \\
\text { Faaliyet } \\
\text { Yaşı }\end{array}$} & $0-5$ Yil & 8 & 4,44 & 0,52 & \multirow{7}{*}{$4,021 \quad 0,001$} \\
\hline & & 6-10 Yil & 24 & 4,17 & 0,87 & \\
\hline & & 11-20 Y1l & 31 & 3,93 & 0,70 & \\
\hline & & 21-30 Yil & 20 & 4,02 & 0,74 & \\
\hline & & $31-50 Y_{11}$ & 13 & 3,66 & 0,47 & \\
\hline & & 51-90 Yil & 22 & 3,40 & 0,54 & \\
\hline & & 91 Y1l ve Üzeri & 22 & 4,09 & 0,69 & \\
\hline \multirow{7}{*}{ Cevap Verme } & \multirow{7}{*}{$\begin{array}{c}\text { Firma } \\
\text { Boyutu }\end{array}$} & $\begin{array}{l}\text { 10'dan Az } \\
\text { Çalışan }\end{array}$ & 16 & 4,34 & 0,65 & \multirow{7}{*}{$-2,221 \quad 0,070$} \\
\hline & & 10-49 Çalışan & 20 & 4,10 & 0,60 & \\
\hline & & 50-249 Çalışan & 29 & 4,03 & 0,95 & \\
\hline & & $250-1999$ & 29 & 3,95 & 1,06 & \\
\hline & & Çalışan & & & & \\
\hline & & 2000 ve Üzeri & 46 & 3.65 & 0.93 & \\
\hline & & Çalışan & & & & \\
\hline \multirow{6}{*}{ Hiz } & \multirow{6}{*}{$\begin{array}{c}\text { Firma } \\
\text { Boyutu }\end{array}$} & 10'dan Az & 16 & 4,25 & 0,52 & \multirow{6}{*}{$2,555 \quad 0,042$} \\
\hline & & Çalışan & & & & \\
\hline & & 10-49 Çalışan & 20 & 3,88 & 0,69 & \\
\hline & & 50-249 Çalışan & 29 & 3,97 & 0,87 & \\
\hline & & 250-1999 & 29 & 403 & 100 & \\
\hline & & Çalışan & & & & \\
\hline
\end{tabular}


2000 ve Üzeri

Çalışan

$46 \quad 3,59 \quad 0,83$

Firma performansı algılarının demografik özellikler açısından farklılıkları

Cinsiyet, medeni durum, çalışma şekli, eğitim düzeyi açısından firma performansı algılarında anlamlı farklılık tespit edilememiştir. Bununla birlikte, grupları arasında anlamlı farklılıklar tespit edilen değişkenlere ait sonuçlar Tablo 16 ve Tablo 17' de listelenmiştir. Bu sonuçlara göre finansal performansta yönetici olanlar ile olmayanlar arasında, yaş ve sektörler arasında, yenilik, finansal ve genel firma performansında firma büyüklüğüne göre $p<0,05$ bulunmuştur.

Tablo16: Firma Performansı t-Testi Sonuçları

\begin{tabular}{|c|c|c|c|c|c|c|c|}
\hline $\begin{array}{l}\text { Firma } \\
\text { PerformansI }\end{array}$ & & Grup & $\mathbf{N}$ & Ort. & SS & $\mathbf{t}$ & $\mathbf{p}$ \\
\hline \multirow{2}{*}{ Finansal } & Yönetici & Evet & 85 & 3,69 & 0,90 & - & \multirow{2}{*}{0,000} \\
\hline & mi? & Hayır & 55 & 4,27 & 0,71 & 4,296 & \\
\hline
\end{tabular}

Tablo17: Firma Performansı ANOVA-Testi Sonuçları

\begin{tabular}{|c|c|c|c|c|c|c|c|}
\hline \multicolumn{2}{|l|}{$\begin{array}{l}\text { Firma } \\
\text { Performansı }\end{array}$} & Grup & $\mathbf{N}$ & Ort. & SS & $\mathbf{F}$ & $\mathbf{p}$ \\
\hline \multirow{4}{*}{ Finansal } & \multirow{4}{*}{ Yaş } & $26-35$ & 34 & 3,38 & 1,03 & \multirow{4}{*}{5,961} & \multirow{4}{*}{0,001} \\
\hline & & $36-45$ & 50 & 3,32 & 1,05 & & \\
\hline & & $46-55$ & 53 & 3,62 & 0,82 & & \\
\hline & & 55'den Büyük & 3 & 3,55 & 1,35 & & \\
\hline \multirow{5}{*}{ Finansal } & \multirow{5}{*}{ Sektör } & Hizmet & 41 & 3,73 & 0,82 & \multirow{5}{*}{2,869} & \multirow{5}{*}{0,026} \\
\hline & & IT & 12 & 3,53 & 0,78 & & \\
\hline & & İmalat & 79 & 4,12 & 0,84 & & \\
\hline & & Perakende & 7 & 3,52 & 1,25 & & \\
\hline & & Tarım & 1 & 3,00 & . & & \\
\hline \multirow{2}{*}{ Finansal } & & $0-5$ Y1l & 8 & 3,71 & 0,76 & \multirow{2}{*}{4,486} & \multirow{2}{*}{0,000} \\
\hline & & 6-10 Y11 & 24 & 4,17 & 0,76 & & \\
\hline
\end{tabular}




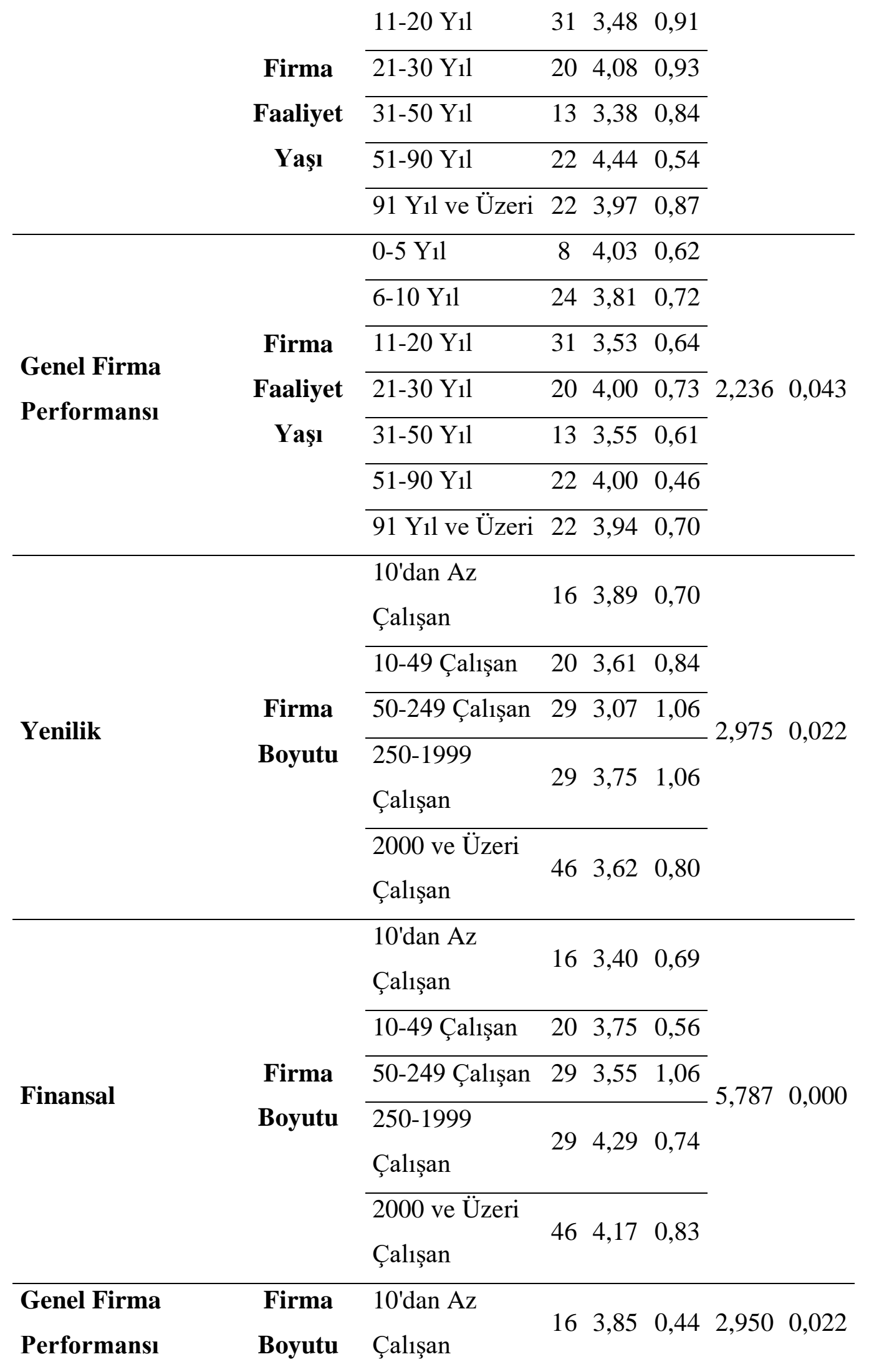




\begin{tabular}{lllll} 
10-49 Çalışan & 20 & 3,75 & 0,56 \\
\hline $50-249$ Çalışan & 29 & 3,47 & 0,65 \\
\hline $\begin{array}{l}\text { 250-1999 } \\
\text { Çalışan }\end{array}$ & 29 & 3,98 & 0,76 \\
\hline $\begin{array}{l}\text { 2000 ve Üzeri } \\
\text { Çalışan }\end{array}$ & 46 & 3,94 & 0,66 \\
\hline
\end{tabular}

\section{Sonuç ve Öneriler}

Yapılan bu çalışmada, örgüt kültürü türleri ile firma performansı değişkeni arasındaki ilişki ve bu ilişkide örgütsel çevikliğin aracılık etkisinin olup olmadığı ampirik olarak test edilmek suretiyle araştırılmıştır. Çalışmanın analizinde değişkenler arasında ilişkide korelasyon katsayıları ve kurulan modelin test edilmesinde yapısal eşitlik modellemesi yöntemi kullanılmışıı. Çalışmanın sonunda klan, adhokrasi ve hiyerarşi kültürleri ile firma performansı arasında, örgütsel çevikliğin aracılık etkisinin bulunduğu tespit edilmiştir. Pazar kültürü ile firma performansı arasında ise örgütsel çevikliğin aracılık etkisi tespit edilememiştir. Ayrıca adhokrasi ve hiyerarşi kültürlerinde, örgütsel çevikliğin tam aracılık, klan kültüründe ise kısmi aracılık rolünde olduğu bulgusuna rastlanılmıştır.

Araştırma sonucunda, çalışanların takım çalışması, işbirliği ve motivasyonlarını artırmaya yönelik algıları pozitif yönde arttığında, işyerinde esneklik, hız, cevap verme çevikliği düzeylerinin de artacağını, çalışanların işyerinde denetime yönelik algıları pozitif yönde arttığında çalışanların çeviklik düzeylerinin de artacağını ileri sürmek mümkündür.

Çalışmadan elde edilen sonuçlar, örgütün genel başarısı ve performansı açısından yapılması gerekenler hakkında yöneticilere yol göstericidir. Yöneticiler tarafından çalışanların motivasyonunun sağlanması, takım çalışmasını güçlendirmeye yönelik faaliyetler ve buna uygun bir örgüt kültürünün yaratılması, çalışanların yönetimle ilgili kararlara yönelik algısını olumlu yönde etkileyecektir. Kültür, örgüt içinde çalışanların birbirleri ve dış çevreyle olan uyumunu artırır. Örgüt yöneticilerinin, çalışanlar arasında iletişimi ve iş birliğini geliştirmeleri, örgütlerde bilgi akışının da güçlenmesini ve örgütün çevredeki olayları gözleme ve izlemede örgütsel kapasitesini artıracaktır. Dolayısıyla örgütlerin üzerinde etki yaratan değişken olayların yer aldığı çevreye, çalışanların yeni bilgileri entegre etmesinde örgüt kültürünün rolü büyüktür. Çevredeki 
değişimi algılamada başarılı olan örgüt çalışanları, karar alma süreçlerinde ve aldıkları kararları uygulamada daha başarılı olurlar.

Çalışmanın kısıtlı bir örneklem ile uygulandığı dikkate alındığında, daha fazla örgüt ve çalışanlar üzerinde araştırılması elde edilen bulguların genellenebilirliğini artıracaktır.

\section{Kaynakça}

Aghina, W., \& Murarka, M. (2021). Going from fragile to agile.

https://www.mckinsey.com/business-functions/organization/our-insights/going-fromfragile-to-agile adresinden alınd 1

Akkaya, B., \& Tabak, A. (2018, Ekşm). Örgütsel Çeviklik Ölçeğinin Türkçeye Uyarlanması: Geçerlik ve Güvenirlik Çalışması. İş ve İnsan Dergisi, 5(2), 185-206.

Antoncic, B., \& Hisrich, R. H. (2001). Intrapreneurship: Construct Refinement and CrossCultural Validation. Journal of Business Venturing, 16, 495-527.

Bulut, Ç., Yılmaz, C., \& Alpkan, L. (2009). Pazar Oryantasyonu Boyutlarının Firma Performansına Etkisi. Ege Akademik Bakış, 9(2), 513-538.

Cameron, K. S. (1985). Cultural Congruence, Strength, and Type: Relationship to Efectivenes. ASHEAnual Meting.

Cameron, K. S., \& Quiin, R. E. (2006). Diagnosing and changing Organizational culture. Based on the competing values framework. New Jersey: Prentice Hall: The Jossey- Bass Business \& Management Series.

Campbell, C. R. (2004). A Longitudinal Study Of One Organization’s Culture: Do Values Endure? Mid-American Journal Of Business, 19(2), 41-51.

Denison, D. (2002). Organizational Culture: Can It Be a Key Lever for Driving Organizational Change. London: Wiley.

Denison, D. R., \& Neale, W. S. (1999). Denison organizational culture survey. ABD: Denison Consulting, LLC.

Deshpande, R., Farley, J. U., \& Webster, F. E. (1993, January). Corporate Culture, Customer • Orientation, and Innovativeness In Japanese Firms: A Quadrad Analysis. Journal of Marketing(57), 23-27. 
E.Porter, M. (1991). Towards a Dynamic Theory of Strategy. Strategic Management Journal, 12, 95-1 17.

Felipe, C. M., Roldán, J. L., \& Leal-Rodríguez, A. L. (2017). Impact of Organizational Culture Values on Organizational Agility. Sustainability, 2354(9), 2-23.

Ginn, J., Stone, M., \& Ekinci, Y. (2010). Opinion Piece Customer retention management in the recession. ournal of Direct, Data and Digital Marketing Practice(12), 115-127.

Hagedoorn, J., \& Cloodt, M. (2003). Measuring Innovative Performance: Is There an Advantage in Using Multiple Indicators? Research Policy(32), 1365- 1379.

Hagedoorn, J., \& Cloodt, M. (2003). Measuring innovative performance: is there an advantage in using multiple indicators? Research Policy(32), 1365-1379.

Jaworski, B. J., \& Kohli, A. K. (1993, July). Market OrientationA:ntecedents and Consequences. Journal of Marketing, 57, 53-70.

Karakılıç, N. Y. (2019, Haziran). Cameron ve Quinn Örgüt Kültürü Ölçeğinin Güvenirlik ve Geçerliğinin Test Edilmesi. KOCATEPEİIBF Dergisi, 21(1), 19-30.

Khalid, Z., R.Madhakomala, \& Purwana, D. (2020). How Leadership and Organizational Culture Shape Organizational Agility in Indonesian SME's. International Journal of Human Capital Management, 4(2), 49-63.

Nafei, W. A. (2016). Organizational Agility: The Key to Organizational Success. International Journal of Business and Management, 11(5), 296-309.

Neely, A., \& Hii, J. (1998). Innovation and Business Performance: A Literature Review. London: University of Cambridge.

Olbert, S., Prodoehl, H. G., \& Worley, C. G. (2017). Organizational agility as a competitive factor: The "agile performer index”. France: NEOMA Business School, Reims Cedex.

Sharifi, H., \& Zhang, Z. (1999). A Methodology for Achieving Agility in Manufacturing Organisations: An Introduction. International Journal of Production Economics, 62(1), $7-22$.

Shin, H., Lee, J.-N., Kim, D., \& Rhim, H. (2015). Strategic Agility of Korean Small and Medium Enterprises and Its Influence on Operational and Firm Performance. Int. J. Production Economics(168), 181-196. 
Uyeno, L. H. (2019). An Empirical Analysis of Company Culture: Using Glassdoor Data to Measure the Impact of Culture and Employee Satisfaction on Performance. Claremont McKenna College.

Uğurlu, Ö. Y., Çolakoğlu, E., \& Öztosun, E. (2019). Stratejik Çevikliğin Firma Performansına Etkisi: Üretim İşletmelerinde Bir Araştırma. İşv ve İnsan Dergisi, 6(1), 93-106.

Venkatraman, N., \& Ramanujam, V. (1987). Measurement of Business Economic Performance: An Examination of Method Convergence. Journal of Management, 13(1), 109-122.

Wageeh, A. N. (2016). Organizational agility: The key to organizational success. International Journal of Business and Management, 11(5), 296-309.

Yllmaz, C., Alpkan, L., \& Ergun, E. (2005). Cultural Determinants of Customer and LearningOriented Value Systems and Their Joint Effects on Firm Performance. Journal of Business Research(58), 1340-1352.

Yilmaz, C., Alpkan, L., \& Ergun, E. (2005). Cultural determinants of customer- and learningoriented value systems and their joint effects on firm performance. Journal of Business Research, 58, 1340-1352.

\section{EK-1}

\section{Firma Performansı Ölçeği}

Müşteri Tutma_1 Kurumumuzun müşteri kaybetme oranı düşüktür.

Müşteri Tutma_2 Kurumumuzun müşteri tutma oranı yüksektir.

Müşteri Tutma_3 Kurumumuzun yeni müşteri kazanma oranı yüksektir.

Yenilik_1

Yenilik_2

Yenilik_3
Kurumumuz yeni ürünlerini ve hizmetlerini rakiplerden önce pazara sunabilmektedir.

Kurumumuzun mevcut ürün ve hizmet yelpazesinde, yeni ürünlerin ve hizmetlerin oranı rakiplerine göre yüksektir.

Kurumumuzun yeni ürün ve hizmet projelerinin sayısı rakiplerine göre yüksektir. 
Yenilik_4

Yenilik_5

Yenilik_6

Yenilik_7
Kurumumuzun iş süreç ve yöntemlerine dair geliştirilen yenilikler rakiplerine göre fazladir.

Kurumumuzda geliştirilen yeni ürün ve hizmet kalitesi rakiplerine göre yüksektir.

Kurumumuzun patent alabilecek ya da patent alınmış yeniliklerinin sayısı rakiplerine göre yüksektir.

Kurumumuzun idari yapı ve zihniyetinin çevresel şartlara göre yenilenmesi rakiplerine göre yüksektir.

Finansal Performans_1 Kurumumuzun Ciro Kârlılı̆̆ı (Kâr/Toplam Satışlar)

Finansal Performans_2 Kurumumuzun Aktif Kârlılığı (Kâr/Toplam Varlıklar)

Finansal Performans_3 Kurumumuzun Genel Kârlılık Durumu 